\title{
Fay Zonu İçinde Açılan Büyük Çaplı Bir Tünelin Kısa ve Uzun Dönem Zemin Parametrelerine Göre Davranışının ve Destek Sistemlerinin Değerlendirilmesi (T36 Tüneli, Ankara-İstanbul Yüksek Hızlı Tren Projesi)
}

\author{
Evaluation of Behavior and Support Systems based on Short and Long Term Soil Parameters of \\ a Large Diameter Tunnel Excavated in Fault Zone \\ (T36 Tunnel, Ankara-Istanbul High Speed Train Project) \\ Ebu Bekir AYGAR ${ }^{1} \mathbb{D}$, Candan GOKCEOGLU ${ }^{2} \mathbb{D}$ \\ ${ }^{1}$ Fugro Sial Yerbilimleri Danışmanlık Mühendislik Ltd., Çankaya, Ankara \\ ${ }^{2}$ Hacettepe Üniversitesi, Jeoloji Mühendisliği Bölümü, Beytepe, Ankara
}

Geliş (Received): 30 Ağustos (August) 2020, Düzeltme (Revised): 21 Eylül (September) 2020, Kabul (Accepted): 02 Kasım (November) 2020

ÖZ

Fay zonu içinde açılan büyük çaplı tüneller için destek sistemi tasarımı her zaman kritik bir mühendislik problemi olmuştur. Fay zonlarında kısa dönemde tünel kazısı sırasında ayna ve tavan stabilite problemleriyle, uzun dönemde ise sıkışmaya bağlı olarak destek sistemlerinde yenilmelerle karşılaşılması muhtemeldir. Bu nedenle destek sistemlerinin tasarımı yapılırken kısa ve uzun dönem zemin parametrelerine göre tasarım detayları dikkate alınmalıdır. Yapılacak olan destek sistemi seçimlerinde en önemli faktörler ortamın jeolojik şartlarını iyi tanımlamak ve jeoteknik tasarım parametrelerinim doğru seçimidir. Bu nedenle, çalışmadaki temel amaç fay zonu içinde açılan Ankara-İstanbul T36 tüneli için kısa ve uzun dönem zemin parametrelerini dikkate alan tahkimat tasarımının incelenmesidir. T36 tünelinin toplam uzunluğu 4100 m olup, 180 m'ye varan örtü yüksekliği altında kazı ve destek çalışmaları tamamlanmıştır. Fay zonu geçişinde ise $115 \mathrm{~m}$ örtü yüksekliği altında tünel desteklemeleri yapılmıştır ve kısa dönemde ayna stabilite problemleriyle uzun dönemde ise tünelde sıkışma problemleriyle ile karşılaşılmıştır. Bu çalışma kapsamında, kısa ve uzun dönemde tüneli etkileyen deformasyonların oluş nedenleri tartışılmakta ve nümerik analizlerle destek sistemleri incelenmektedir. Bununla birlikte, tünelcilik açısından önemli konulardan biri olan fay zonu geçişlerine ilişkin ölçütler tartışılmaktadır.

Anahtar Kelimeler: Fay Zonu, Hızlı Tren Projesi, Tünel Destek Sistemi

\section{ABSTRACT}

Support system design has always been a critical engineering problem for large-scale tunnels excavated within fault zones. In fault zones, it is possible to encounter face and ceiling stability problems encountered during the tunnel excavation in the short term and failures in the support systems due to squeezing in the long term. For this reason, when designing support systems, short-term and long-term parameters should be considered. The most important factors in selecting the support system to be installed are to describe the geological conditions well and the correct selection of geotechnical design parameters. Therefore, the main purpose of this study is to investigate 
Aygar, Gokceoglu

the support design that considers the short- and long-term parameters for the Ankara-Istanbul High Speed Train Project, T36 tunnel excavated within the fault zone. The total length of the T36 tunnel is $4100 \mathrm{~m}$, and excavation and support works have been completed under a maximum overburden thickness of $180 \mathrm{~m}$. In the fault zone transition, the supports were made under the overburden thickness of $115 \mathrm{~m}$, and face stability problems were encountered in the short term and squeezing problems in the tunnel in the long term. In this study, the causes of deformations in the tunnel affecting the tunnel in the short and long term are discussed and numerical analysis and support systems are examined. Moreover, the criteria for fault zone crossings, which is one of the most important issues for tunneling, are discussed.

Keywords: Fault Zone, High Speed Train Project, Tunnel Support System

\section{GIRIŞ}

Geniş çaplı tünellerin kazısı sırasında yaşanan sorunlar temelde benzerlikler göstermektedir. Bunlar; (a) Tünel tavan stabilitesi, (b) Tünel ayna stabilitesi ve (c) Sıkışma problemleridir. Zayıf zeminlerde kısa dönemde, diğer bir anlatımla tünel kazısı sırasında meydana gelen tavan stabilite problemleriyle ayna stabilite problemleri; sürenler ve ayna zemin çivileri gibi desteklerle çözümlenebilmektedir. Burada hesaplamalar kısa dönem parametrelerine göre yapılarak destek sistemleri boyutlandırılmaktadır. Uzun dönemde ise, tünel stabilite problemleri genelde sıkışmaya bağlı olarak gelişmekte olup, destek sistemi tasarımı uzun dönem parametreleri dikkate alınarak yapılmalıdır. Özellikle bu tür ortamlarda açılacak tünellerde iç kaplama betonu uzun dönemde kritik olup, kesinlikle donatısız yapılmamalıdır (Aygar, 2020). Büyük çaplı tünellerde fay geçişi destek sistemleri Aygar (2000; 2007) tarafından incelemiş ve rijit destek sistemlerinin uygulanması gerekliliği belirtilmiştir. Kısa dönemde tahkimatlarda herhangi ciddi bir sorun bulunmazken, uzun dönemde sıkışmaya bağlı olarak tünel desteklerin yenildiği gözlenmiştir (Aygar, 2000; 2007). Ankara-İstanbul Yüksek Hizlı Tren Projesi kapsamında inşa edilmiş olan T13 tünelinde killi fay zonu geçişinde karşılaşılan sorunlar ve çözüm önerileri Aygar ve Gökçeoğlu (2019) tarafindan ortaya konmuştur. Uzun dönemde bazı zeminlerin şişme ve sıkışma davranışı göstermesi nedeniyle, literatürde sıkışmaya bağl1 deformasyonların önlenmesi için deformasyon boşluklarının tasarımının gerekliliğine vurgu yapılmıştır (Schubert, 1996; Hoek, 2007). Fay zonlarında zeminlerin desteksiz durma süresinin çok kısa olması nedeniyle, tahkimatın beklenmeden yapılması gerekliliği Terzaghi (1946) ve Bienawski (1973, 1976 ve 1989) tarafından belirtilmiştir. Temelde belirli bir miktarda deformasyona izin verilmesiyle tahkimat basıncını azalmayı hedefleyen Yeni Avusturya Tünel Açma Yöntemi (NATM) Rabcewicz (1964a, 1964b ve 1965) tarafindan önerilmiştir. Daha sonra yöntem Rabcewicz ve Golser (1973) ile Müller (1978) tarafindan geliştirilmiştir. Ancak daha sonraki dönemlerde, zayıf zeminlerde ve fay zonlarındaki tünellerde esnek bir dış kemer ve deformasyonlara izin verilmesinin stabilite üzerinde olumsuz etkisinin bulunduğu ve rijit bir desteklemenin zorunlu olduğu belirtilmiştir (Aygar, 2020). Çözüme yönelik olarak, fay zonlarında ve derin tünellerde yaşanan sorunlar incelenerek, zayıf zemin tünelciliği literatürüne katkıda bulunmuşlardır (Mahmutoğlu vd., 2006; Hoek, 2007 ve 2012; Hoek ve Guevera, 2009). Bununla birlikte, zayıf zeminler içinde açılan bir tünelin stabilitesi ile portal stabilitesinin tünel stabilitesi üzerindeki etkileri de Aygar ve Gökçeoğlu (2020a ve b) tarafından tartışılmış ve çözüm önerileri ortaya konulmuştur. Özellikle fay zonu içinde açılan tünellerde zayıf zeminlerin varlığı, yüksek su 
basınçları gibi olumsuz jeolojik ve jeoteknik koşullar, her bir tünel için özel mühendislik çözümünü gerektirmektedir. $\mathrm{Bu}$ çözümler gelecekte yapılacak tünel çalışmalarına katk1 sağlayacaktır. Bu çalışmada, fay zonunda açılan geniş çaplı T36 tünelinin fay zonu geçişinde karşılaşılan sorunlar ile uzun ve kısa dönem zemin parametrelerine göre destek sistemi analitik çözümler ve nümerik analizlerle incelenmiş olup elde edilen sonuçlar tartışılmıştır.

\section{T36 TÜNELINIIN GENEL ÖZELLIKKLERİ}

T36 tüneli Ankara İstanbul Yüksek Hızlı Tren Projesi kapsamında, Km:239+933.00 ile Km:244+033.00 arasinda olup, toplam uzunluğu 4100 m'dir (Şekil 1). Tünel girişinin topoğrafik yüksekliği 830 m'dir ve tünelin çıkış kotu 1030 m seviyesine erişmektedir. Tünel üzerindeki örtü kalınlığ 6 ile $183 \mathrm{~m}$ arasında değişmektedir (Fugro Sial, 2009). Bu çalışma kapsamında, $\mathrm{Km}: 242+960$ ile Km:243+100 arasinda yer alan $140 \mathrm{~m}$ uzunluğundaki fay zonunda meydana gelen aşırı deformasyonların mekanizması ile kısa ve uzun dönem zemin parametreleri kullanılarak yapılan analizlerden elde edilen sonuçlar tartışılmaktadır. Diğer bir ifade ile bu çalışmada tünelin tamamı değil sadece $\mathrm{Km}: 242+960$ ile $\mathrm{Km}: 243+100$ aralığ 1 dikkate alınmaktadır. Tünel güzergahının Google Earth görüntüsü ve planı Şekil 1'de verilmektedir. Tek tüp olarak projelendirilen T36 tünelinin yüksekliği 8 m olup, kazı çapı 13.5 m'dir (Şekil 2).

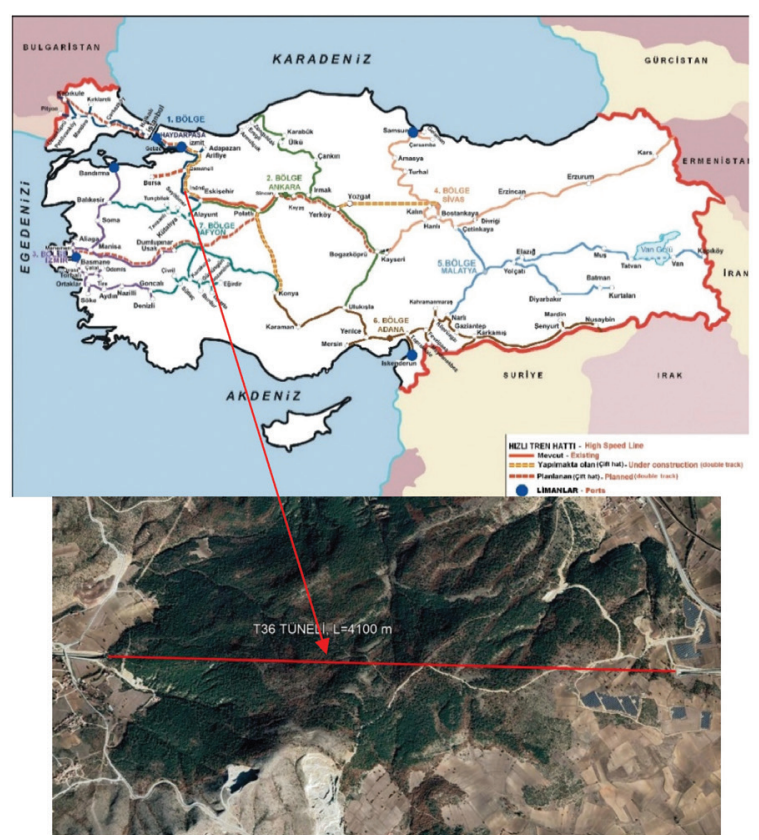

Şekil 1. T36 Tüneli lokasyon haritası ve Google Earth görüntüsü üzerindeki tünelin giriş ve çıkışları.

Figure 1. Location map of the T36 tunnel and its entry and exit portals on Google Earth view.

T36 tüneli Yeni Avusturya Tünel Açma Yöntemine göre projelendirilmiştir (Rabcewicz, 1964a, 1964b and 1965; Rabcewicz and Golser, 1973; Müller, 1978). Tünelde deformasyonların meydana geldiği Km:242+960 ile Km:243+100 kesiminin fay zonu içinde $(140 \mathrm{~m})$ yer alması ve örtü yüksekliğinin $115 \mathrm{~m}$ olması nedeniyle tünelde sıkışmaya bağlı olarak deformasyonlar da meydana gelmiş ve tünelin bu kesimde iç kaplama öncesinde tarama kazısı gerçekleştirilmiştir. 


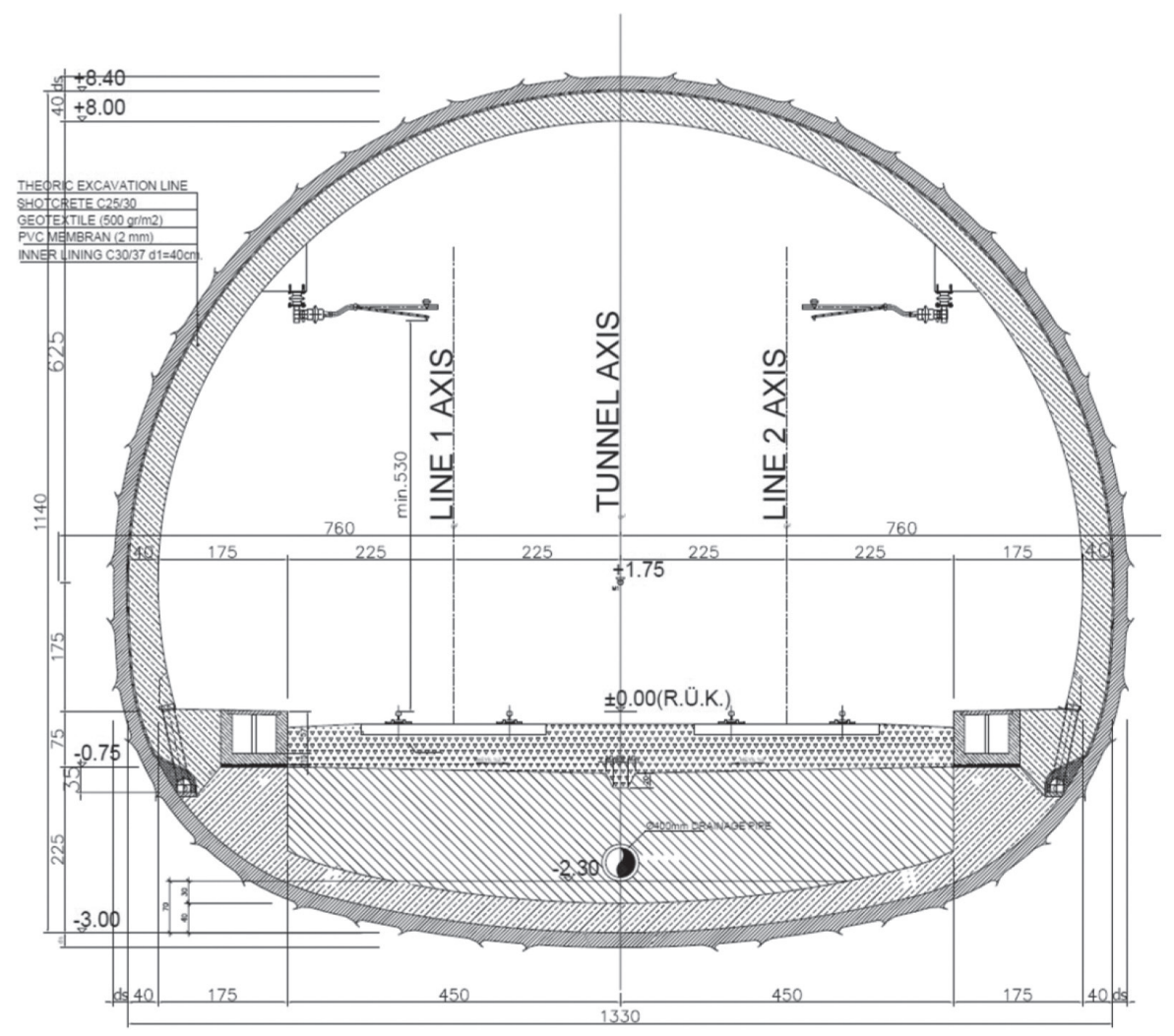

Şekil 2. T36 Tüneli tip kesiti.

Figure 2. Typical cross-section of the T36 tunnel.

\section{Jeolojik-Jeoteknik Koşullar}

T36 nolu tünelinin tamamı Miyosen yaşlı Porsuk Formasyonunun gevşek-zayıf çimentolu tortul kaya birimleri içerisinde açılmıştır. Tünel seviyesinde, Porsuk Formasyonunun kahveyeşil-alacalı, zayıf çimentolu çakıltaşı-kumtaşıkiltaşı seviyelerine rastlanılmıştır. Formasyon ayrışma nedeniyle hemen hemen kayaç özelliğini yitirmiş ve zayıf kayaç-sert zemin sınırında özelliklere sahip bir geçiş kayacına dönüşmüştür. $\mathrm{Bu}$ özelliklere bağlu olarak, birim dayanım açısından son derece zayıftır. Kil-kiltaşı seviyelerinin formasyon içinde hakim birimleri oluşturduğu görülmüsstür (Şekil 3 ve 4). Porsuk Formasyonu'nun kil-kiltaşı seviyeleri geçirimsiz kaya özelliğindedir ve bu kesimlerde çok hafif sızıntı şeklinde yeraltısuyu ile karşılaşılmıştır. Bahsedilen zemin özellikleri nedeniyle, tünelin tamamının çok baskılı kayaç kütlesi C3 destek sınıfinda projelendirilmesi önerilmiştir (Fugro Sial, 2011). Ancak, uygulama aşamasında yer yer farklı kaya kütleleriyle karşılaşılmış ve tünel kazısı bu tür zeminler içerisinde sürdürülmek zorunda kalınmıştır. Fay zonunun ise baskılı kayaç kütlesi, C2 destek sınıfinda yer aldığına karar verilmiş ve tünel kazısı bu kapsamda yapılmıştır. $\mathrm{Bu}$ nedenle tünelde uzun dönemde deformasyonlar meydana gelmiştir. C2 destek sınıfına giren kayaç kütlelerinde meydana gelen deformasyonlar orta derecede fakat belirgin olarak uzun süreli ve yavaş ilerlerken, 
C3 destek sınıfında, başlangıçta yüksek ve hızlı deformasyonlar gelişir. C2 destek sinıfinda benzer şekilde deformasyonlar uzun sürer ve yavaş son bulur. C3 destek sınıfinda derine inen kırılmalar ve plastik bölgeler gözlenir. Tüm bu veriler dikkate alındığında, T36 tünelinin çok baskılı sıkışan ve şişen zemin-kaya ortamları içinde yer aldığı ortaya çıkmaktadır (Şekil 3 ve 4).

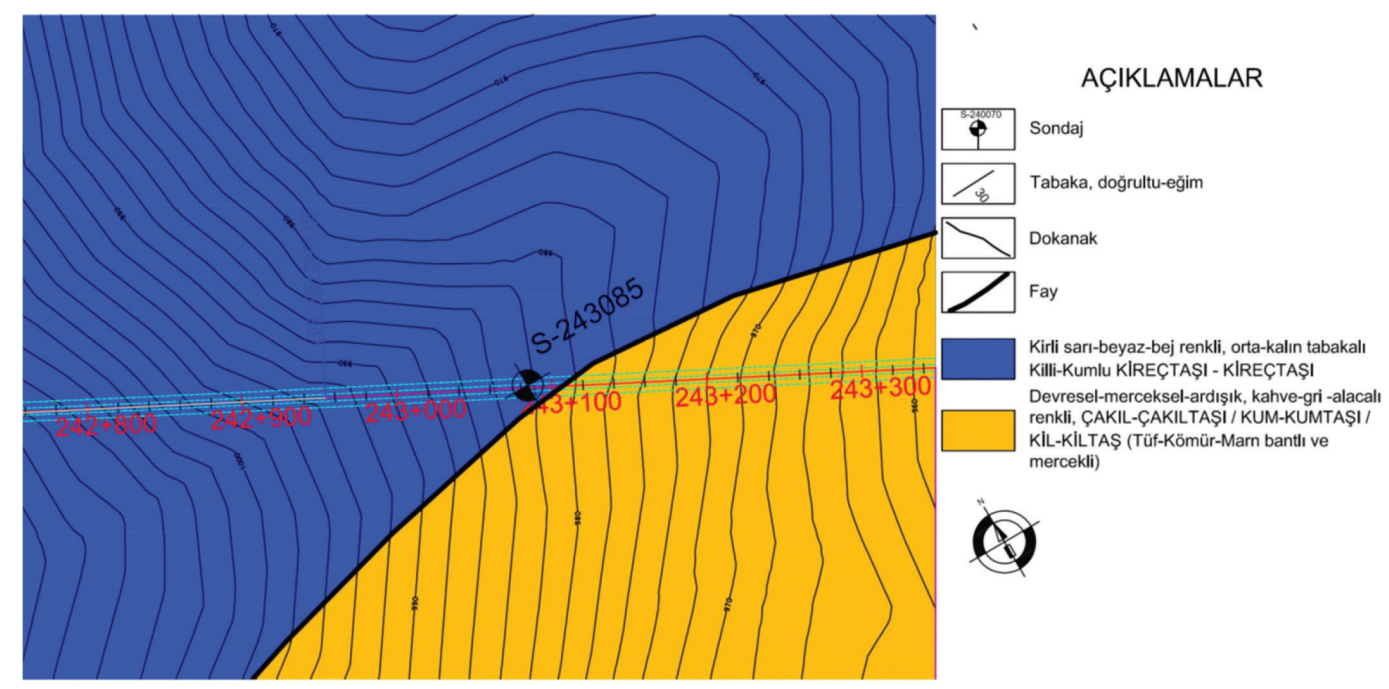

Şekil 3. Km:242+800 $-243+300$ arası kesiminin jeoloji haritası (Fugro Sial, 2009).

Figure 3. Geological map of the section between Km:242+800 - 243+300 (Fugro Sial, 2009).

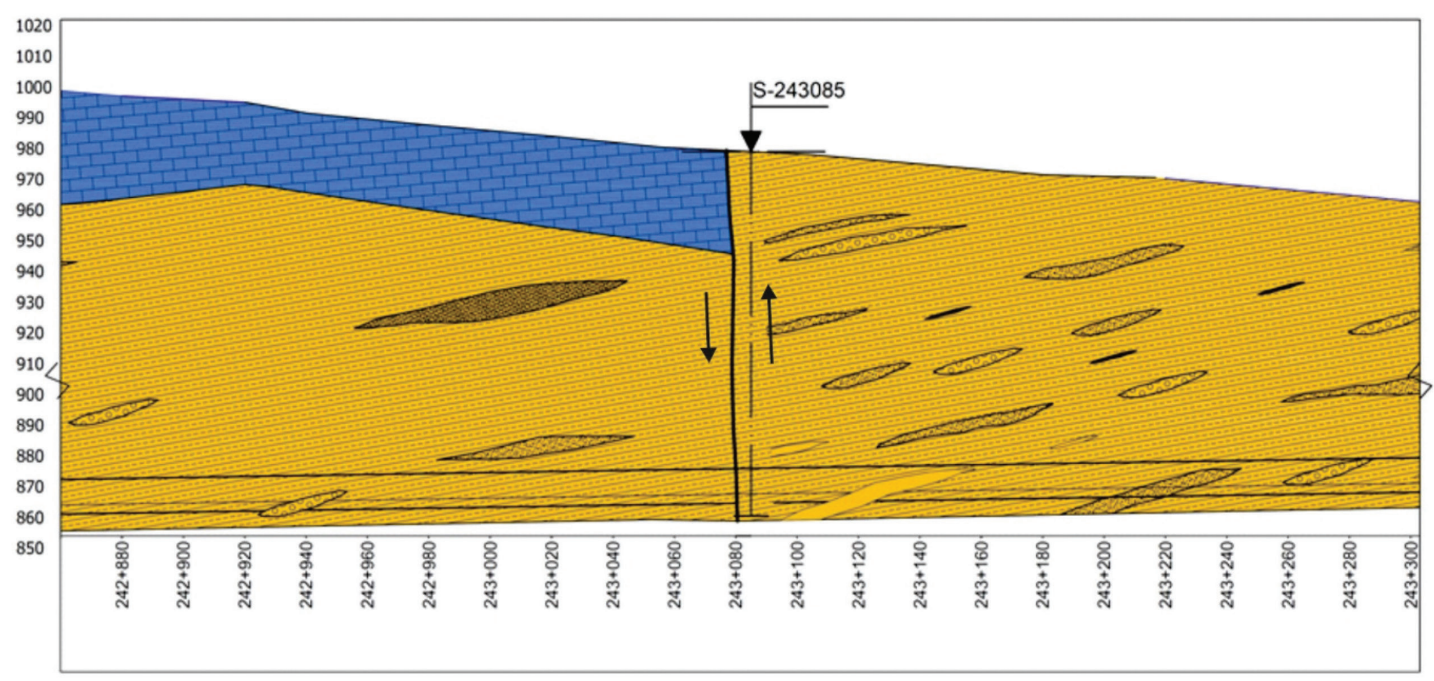

Şekil 4. T36 tünelinin Km:242+800 - 243+300 arası jeolojik kesiti (Fugro Sial, 2009).

Figure 4. Geological cross section of the T36 tunnel of Km:242+800 - 243+300 (Fugro Sial, 2009). 
Tünelde deformasyonların meydana geldiğ arazi kesiminde SK243+085 nolu sondaj proje aşamasında Fugro Sial (2009) tarafindan gerçekleştirilmiştir. Marn mercekli kiltaşı ile kireçtaşı arasında düşey bir dokanak fayı yer almaktadır (Şekil 3 ve 4). Sondaj, dokanağa çok yakın, killi kireçtaşları içinde açılmış ancak fay zonunu kesecek şekilde konumlandırılmıştır. Sondajda koyu yeşilimi gri, çakı1lı, aşırı konsolide sert kil-son derece zayıf dayanıml birimler kesilmiştir (Fugro Sial, 2009). Sondaj profili boyunca yer yer fay breşleriyle karşılaşılmıştır. Bu tür zonlar boyunca karotlar üzerinde gerçekleştirilen ölçümlerden RQD değerleri $\% 0$ ile $\% 5$ arasında elde edilmiştir. Sondajda örselenmemiş numune alınamadığ 1 için aynı birim içerisinde yeralan çıkış portalı bölgesinden örnekleme ekipmanı kullanılarak alınan örselenmemiş numuneler üzerinde deneyler gerçekleştirilmiştir. Fugro Sial (2009) tarafından gerçekleştirilen deneyler; eksenel ve çapsal deformasyonları dikkate alan tek eksenli deformabilite deneyi, konsolidasyonsuzdrenajsız(UU) üç eksenli sıkışma, ve birim hacim ağırlık deneyleridir. Deney sonuçları Çizelge 1'de toplu olarak sunulmaktadır. Deneyler ASTM ve TSE standartlarına göre yapılmıştır.
Alınan numuneler, olabildiğince tüneli temsil etmesi amaciyla yüzeyden örnekleme yapılarak seçilmiştir. $\mathrm{Bu}$ numunlerden 3 nolu blok tamamen zemin özelliği taşırken 2 ve 4 nolu örnekler ise sert zemin-zayıf kaya sınırındadır. Çizelge 1'de verilen deney sonuçları kullanılarak yapılan değerlendirmeleraşağıda sırasıyla anlatılmıştır. Birimin kısa ve uzun dönem parametreleri Çizelge 2'de verildiği gibi tayin edilmiştir. Kısa dönem parametrelerinde kohezyon değeri olarak $150-200 \mathrm{kPa}$ ve içsel sürtünme açısı da $15-17^{0}$ olarak alınmıştır. Uzun dönem efektif parametreler ise Gibson (1953) ve Terzaghi vd. (1996) tarafından verilen eşitlikler yardımıyla belirlenmiştir. Efektif içsel sürtünme açısı ile plastitsite indisi, PI arasındaki ilişkki Şekil 5' de verilmiştir.

Laboratuvar çalışmalarından elde edilen sonuçlara göre ortalama PI değeri \%30 olarak $(\omega P l=\% 30)$ olarak Fugro Sial (2009) tarafindan saptanmış olup, bu değere karşılık gelen efektif içsel sürtünme açısı $28^{\circ}$, uzun dönem kohezyon değeri ise $25 \mathrm{kPa}$ olarak belirlenmiştir.

Çizelge 1. T36 çıkış portalından alınan blok numuneler üzerinde yapılan deneylere ait sonuçlar (Fugro Sial, 2009).

Table 1. Results of experiments on the block samples taken from T36 exit portal (Fugro Sial, 2009).

\begin{tabular}{cccccccc}
\hline Numune No & Birim & $\begin{array}{c}\text { Elastisite } \\
\text { Modülü }\end{array}$ & $\begin{array}{c}\text { Poisson } \\
\text { Oranı }\end{array}$ & $\begin{array}{c}\text { Tek Eksenli } \\
\text { Sikışma Dayanımı }\end{array}$ & $\begin{array}{c}\text { Birim Hacim } \\
\text { A ğılık }\end{array}$ & $\begin{array}{c}\text { Üç Eksenli } \\
\text { Sıkş̧ma Deneyi } \\
\text { (UU) }\end{array}$ \\
\hline Blok 2 & Kiltaş1 & 234 & 0.25 & 1.04 & $\mathrm{kN} / \mathrm{m}^{3}$ & $\mathrm{c}(\mathrm{kPa})$ & $\phi^{\circ}$ \\
\hline Blok 3 & Kiltaş1 & 201 & 0.27 & 0.24 & 19.10 & 210 & 14 \\
\hline Blok 4 & Kiltaş1 & 4250 & 0.15 & 3.78 & 22.30 & 138 & 20 \\
\hline
\end{tabular}




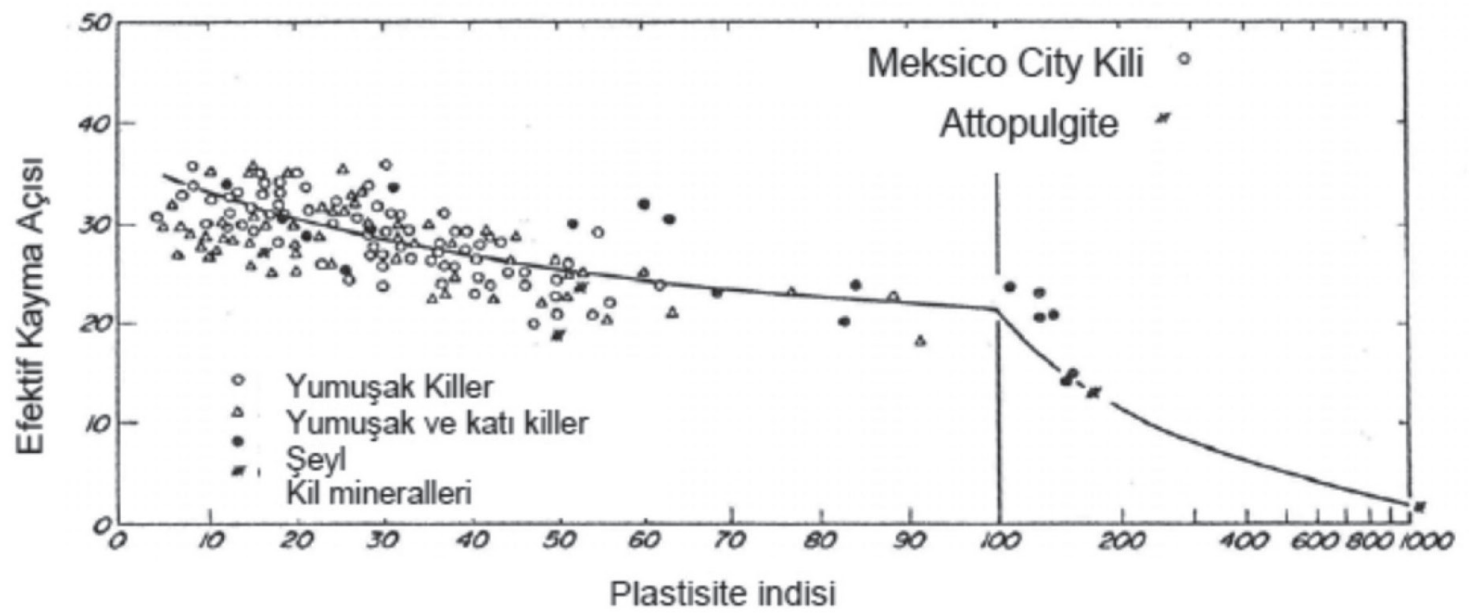

Şekil 5. Efektif Sürtünme Açısı ile Plastisite indisi (PI) arasındaki ilişki (Terzaghi vd., 1996).

Figure 5. The relationship between the Effective Friction Angle and the Plasticity Index (PI) (Terzaghi et al., 1996).

Çizelge 2. Fay zonu bölgesi için önerilen jeoteknik tasarım parametreleri (Fugro Sial, 2009).

Table 2. Proposed geotechnical design parameters for the fault zone area (Fugro Sial, 2009).

\begin{tabular}{cccc}
\hline & $\begin{array}{c}\text { Doğal } \\
\text { birim } \\
\text { hacim } \\
\text { Parametre tipi } \\
\text { ağılık } \\
\gamma_{\mathrm{n}} \\
\left(\mathrm{kN} / \mathrm{m}^{3}\right)\end{array}$ & $\begin{array}{c}\text { Makaslama } \\
\text { Dayanım } \\
\text { Parametreleri } \\
(\mathrm{kPa})\end{array}$ & $\begin{array}{c}\varnothing \\
\left({ }^{\circ}\right)\end{array}$ \\
\hline $\begin{array}{c}\text { Drenajsız Dayanım } \\
\text { Parametreleri (k1sa } \\
\text { dönem) }\end{array}$ & 19.0 & $150-200$ & $15-17$ \\
\hline $\begin{array}{c}\text { Drenajlı Dayanım } \\
\text { Parametreleri } \\
\text { (uzun dönem) }\end{array}$ & 19.0 & 25 & 28 \\
\hline
\end{tabular}

\section{T36 Tünelinde Karşılaşılan Sorunlar}

Tünelde deformasyonların meydana geldiği Aralık 2011 döneminde, tünel kazısı üst yarı aynasinda Km:242+960.00'da, alt yarı aynasinda $\mathrm{Km}: 243+006$ ve tünel taban kemerinde (invertte) ise Km:243+009'da kazılar devam etmekteydi. Tünelin tamamlanan kesimlerinde invert betonu
Km:243+045'e kadar (36 m) tamamlanmıştır. Tünelde meydana gelen deformasyonlar ise $\mathrm{Km}: 243+100$ 'den itibaren başlamıştır. Hazırlanan jeolojik profilden (Şekil 4) ve tünel ayna fotoğraflarından da (Şekil 6) görüleceği gibi tünelin bu kesimi fay zonu içerisinde kalmaktadır. Tünel Km:243+150'den itibaren siltli, kumlu ve killi zayıf çimentolu bir malzeme içerisinde, yer yer çok yumuşak kil/çamurtaş1 içinden geçilmiştir. Kil seviyeleri içinden sızıntı şeklinde su gelişinin olduğu gözlenmiştir. Daha sonra Km:243+105'lerden itaberen tünel, sik kayma düzlemleri içeren (shear zones) yeşil renkli çok ayrışmış kiltaşı içinde kalmaktadır. Km:243+090'dan itibaren ise tünel, kahverengi yeşil renkli çok ayrışmış, orta-yüksek plastisitide kohezyonlu zemin özelliği gösteren fay kili, fay breşi içerisinden devam etmiştir. Killer içerisinde yer alan çakıl mercekleri içerisinden su akışı olmuştur (Fugro Sial, 2011). Bir anlamda tünelin Km:243+085 ile Km:243+115 aras1 fay zonunun etki alanı olarak düşünülebilir. Tüm deformasyonlar ve tahkimat sistemlerindeki çatlaklar bu bölgede yoğunlaşmıştır. 


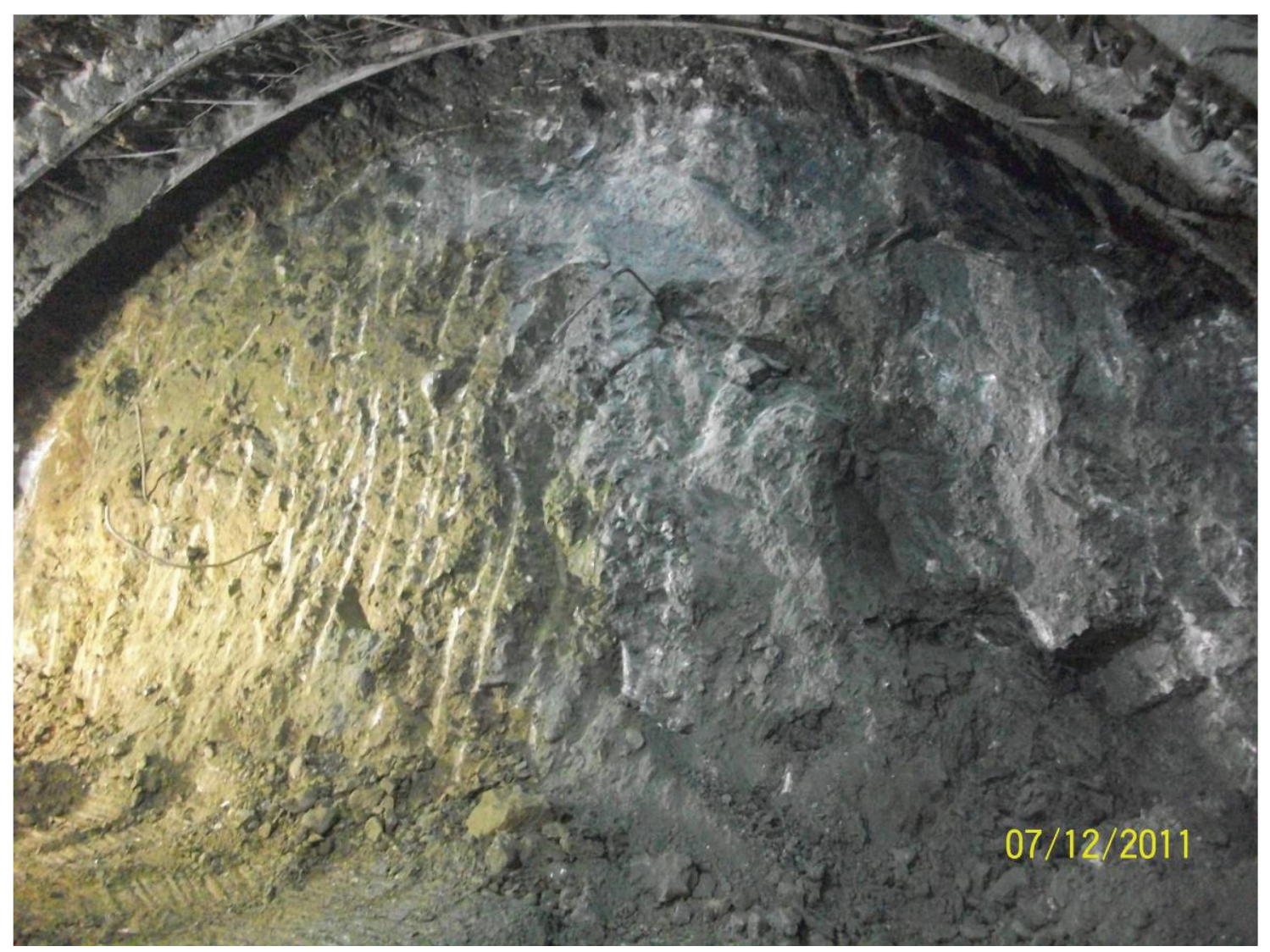

Şekil 6. Tünel üst yarı kazı aynası.

Figure 6. Top heading excavation face of the tunnel.

Deformasyonların meydana geldiği bu kesimin tamamı, projelendirme aşmasında C3 kaya sınıfında tamamlanmıştır. Ancak uygulama aşamasında bu kesimler için C2 kaya sınıfı dikkate alınmıştır. Tünelde meydana gelen deformasyonların sonucunda, püskürtme betonda çatlaklar ve yenilmeler (Şekil 7) meydana gelmiştir. Oluşan bu deformasyonların büyük bir bölümü tünelin en kritik yeri olarak üst ve alt yarı birleşim noktalarında görülmüştür (Şekil 8). Deformasyonlar öncesinde tünelin bu bölümünde invert betonları tamamlanmıştır (Şekil 9). 


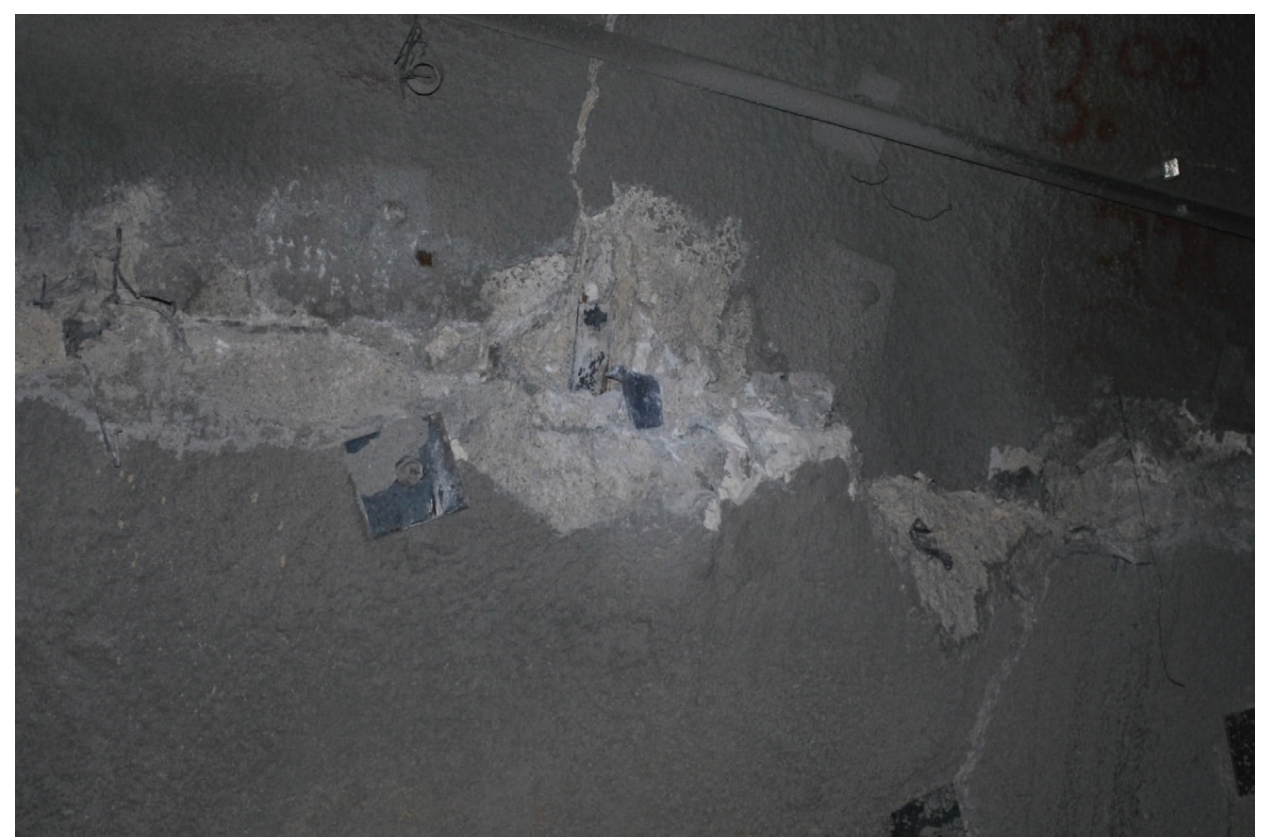

Şekil 7. Püskürtme betonda meydana gelen çatlaklar.

Figure 7. Cracks occured in the shotcrete.

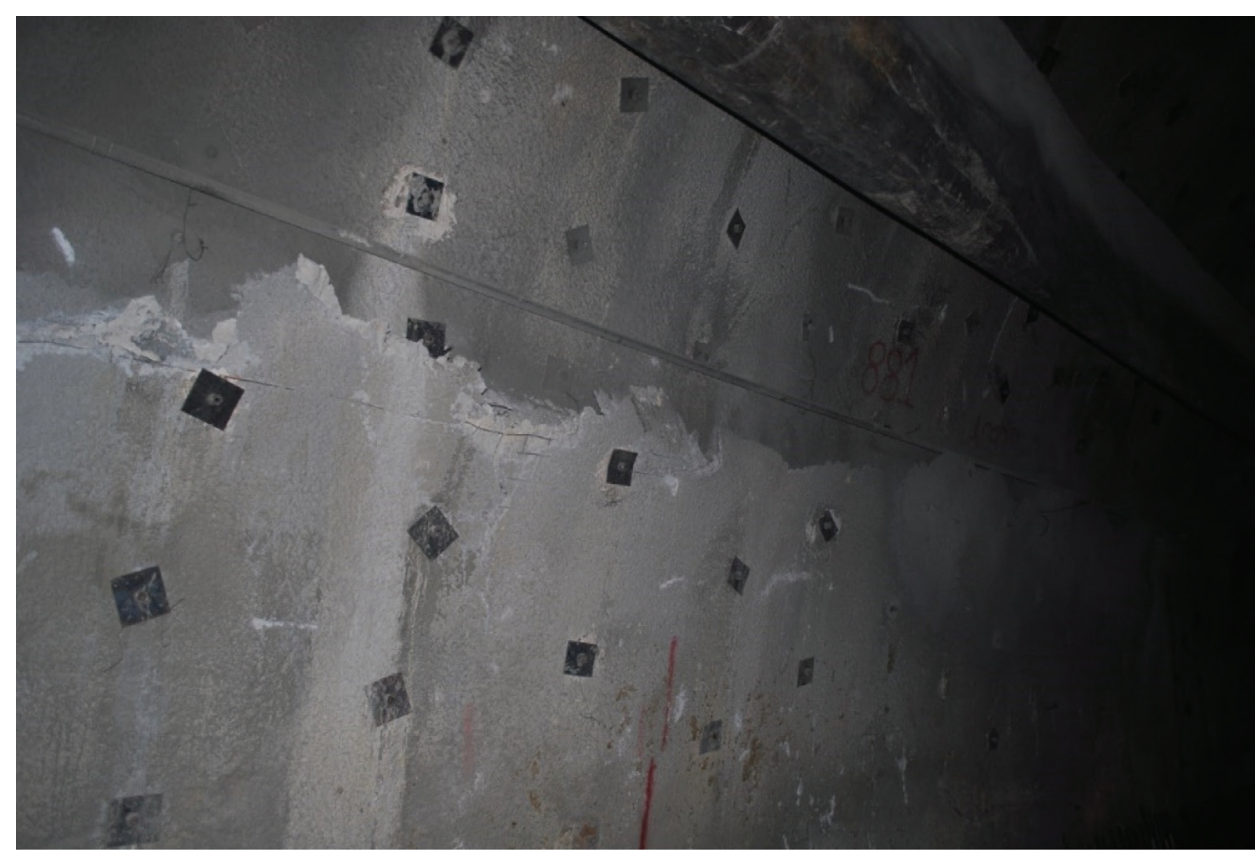

Şekil 8. Alt yarı ve üst yarı birleşimindeki püskürtme beton birleşim bölgesinde meydana gelen çatlaklar. Figure 8. Cracks occured in shotcrete at the junction of the bench and top heading. 
Aygar, Gokceoglu

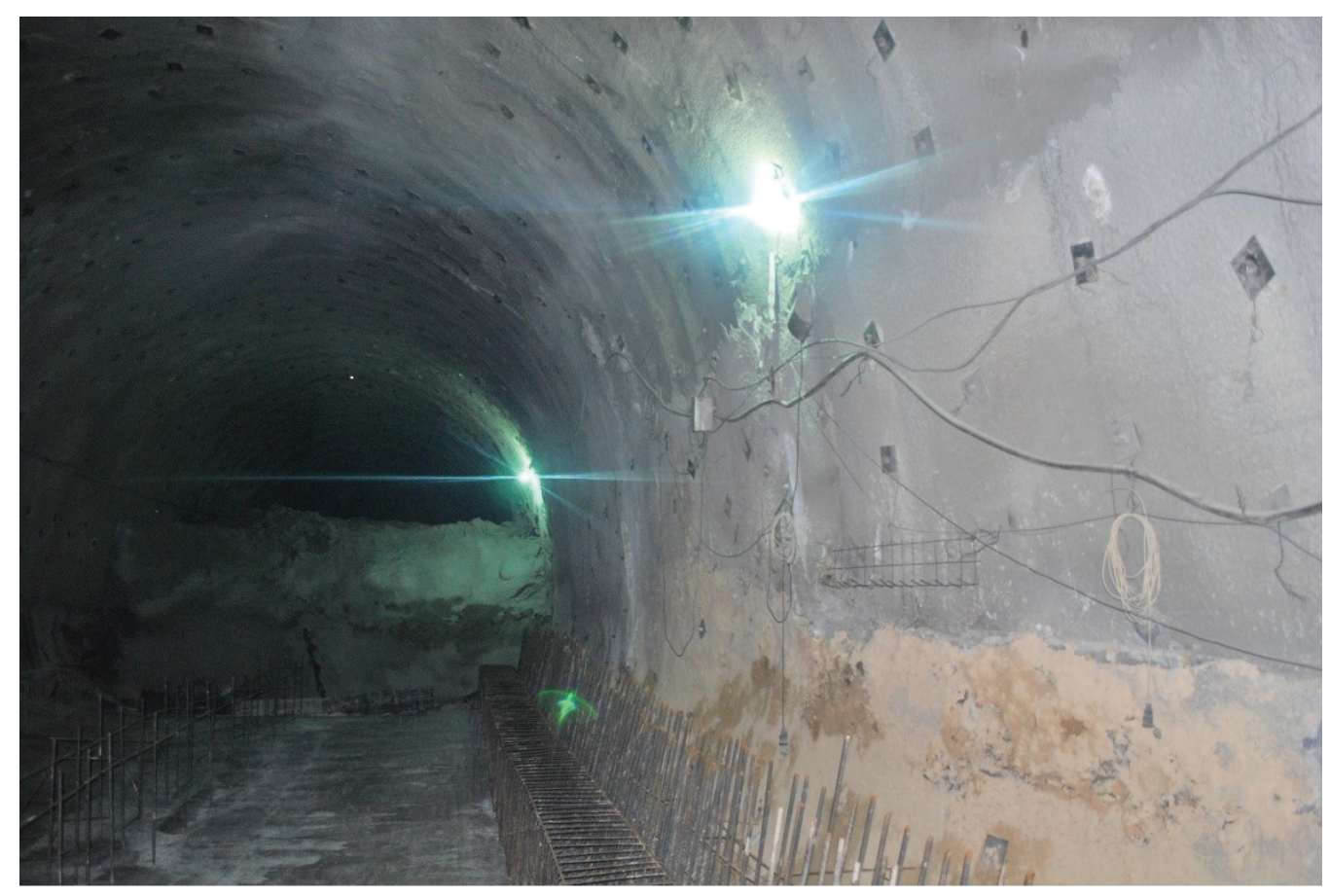

Şekil 9. Tünelin taban kemer betonunun tamamlanmış hali.

Figure 9. Completed state of the invert concrete of the tunnel.

Deformasyonların meydana geldiği kesimlere ait konverjans ölçüm sonuçlar Şekil 10 ve 11'de verilmiştir. Tünel içi deformasyon (Konverjans) ölçümleri iki nokta arasındaki kapanmayı ölçmek amacıyla şerit ekstonsometreler aracılığıla yapılmaktadır. Konverjans ölçümlerinden görüleceği gibi, tünel alt yar1 kazıları sırasında deformasyonlarda k1sa sürede ciddi bir artış meydana gelmiştir (Şekil 10 ve 11). Şekil 10 ve 11 de belirlenen ölçümler 1 nolu seri, 1 ve 2 nolu noktalar arasını, 2 nolu seri, 1 ve 3 nolu noktalar arasinı, 3 nolu seri 1 ve 4 nolu noktalar arasını, 4 nolu seri 1 ve 5 nolu noktalar arasını, 5 nolu seri 2 ve 3 nolu noktalar arasinı ve 6 nolu seri ise 4 ile 5 nolu noktalar arasındaki kapanmayı göstermektedir.

Km:243+021.00'de yapılan ölçümlerde görüleceği gibi 2-3 nolu noktalar arasındaki konverjanslar 5 gün içinde $26 \mathrm{~cm}$ artmış ve toplam 60 cm'ye ulaşmıştır (Şekil 10). Meydana gelen deformasyonların alt yarı kazısı sırasında oluştuğu görülmektedir. Bununla beraber Km:243+043.00'da yapılan ölçümlerde de 2-3 nolu noktalar arasındaki kapanmalarda 5 gün içerisinde $15 \mathrm{~cm}$ artmış ve toplam kapanma 37 cm'ye ulaşmıştır (Şekil 11). 


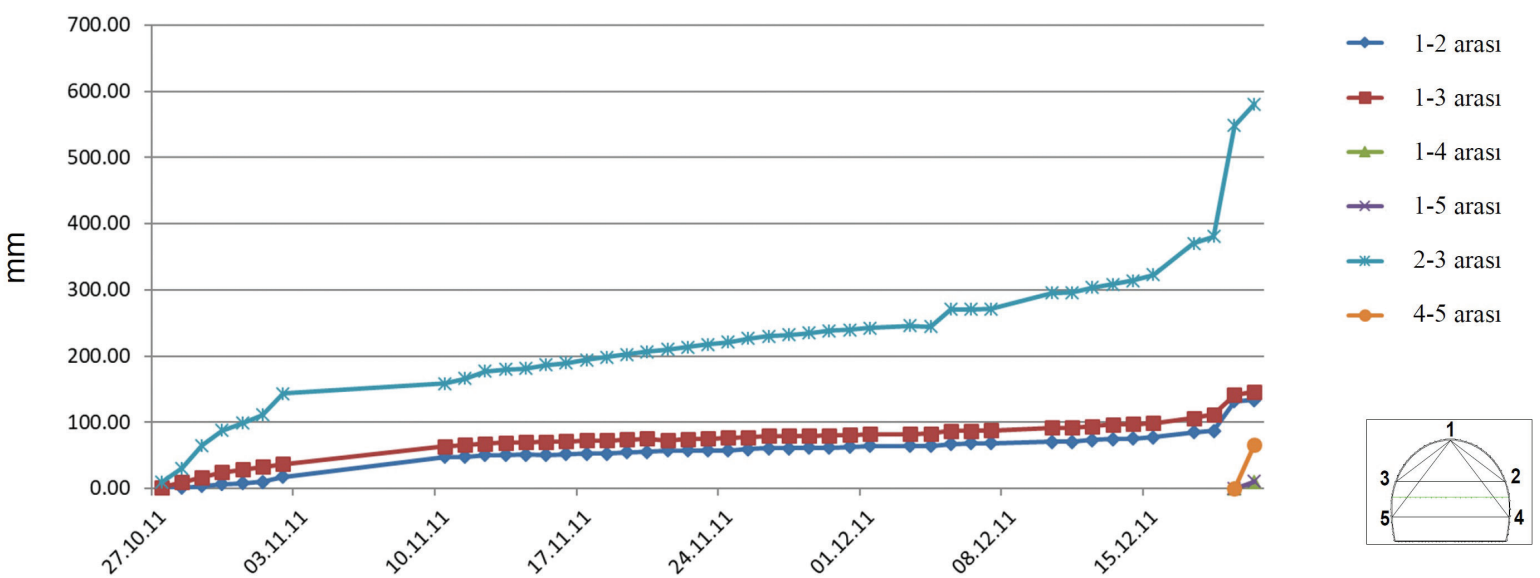

Şekil 10. Km: 243+021'de yapılan konverjans ölçümleri (Fugro Sial, 2011).

Figure 10. Convergence measurements at Km:243+021 (Fugro Sial, 2011).

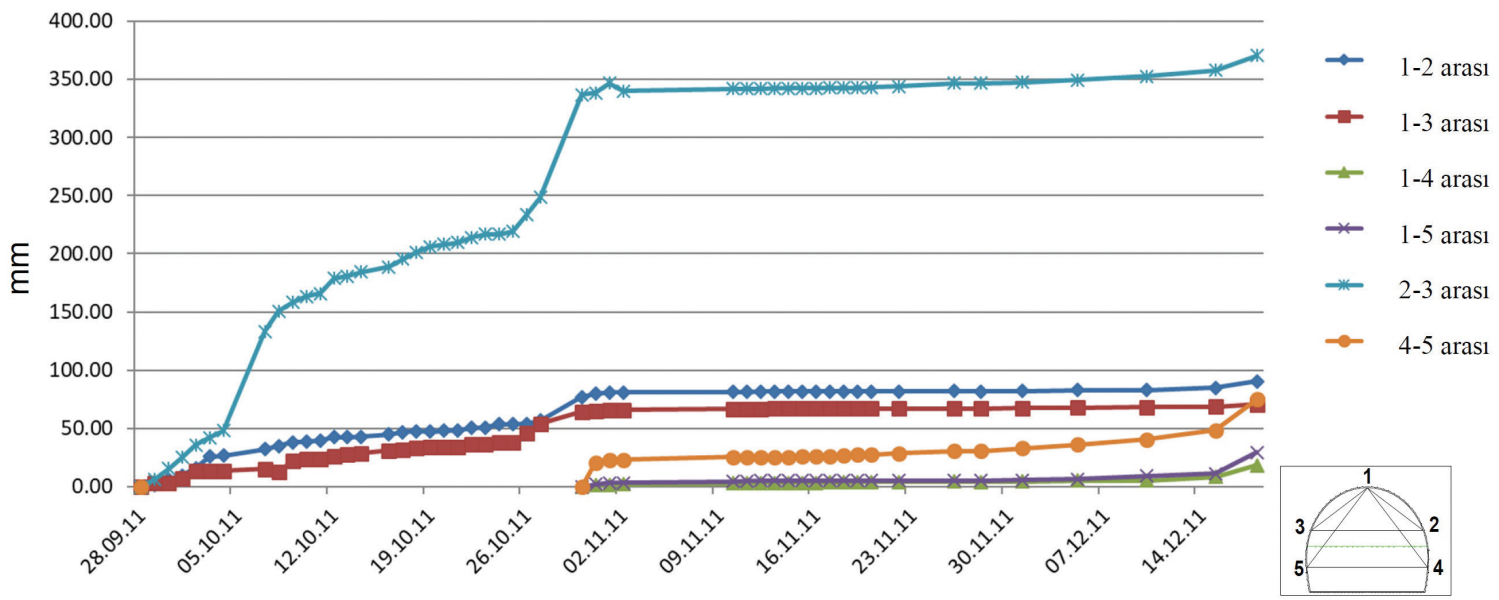

Şekil 11. Km:243+043'de yapılan konverjans ölçümleri (Fugro Sial, 2011).

Figure 11. Convergence measurements at Km:243+043 (Fugro Sial, 2011).

\section{Tünel Destek Sistemi Analizleri}

Tünel destek sistemlerinin belirlenmesinde üç ana yaklaşım;

a) Ampirik yaklaşımlar (Bieniawski, 1973, 1976 ve 1989; Barton vd., 1974 ve 1980; Grimstad ve Barton, 1993), b) Analitik yaklaşımlar,

c) Sayısal analiz yöntemleri.

$\mathrm{Bu}$ yaklaşımlar içerisinde sayısal analizler günümüzde tüm tünel projelerinin vazgeçilmez bir parçası olarak kullanılmaktadır (Koçkar ve Akgün, 2003; Akgün vd., 2014; Zou vd., 2019; Moussaei vd., 2019; Panthi ve Basnet, 2019; 
Aygar, Gokceoglu

Aygar ve Gökçeoğlu, 2020c; 2020d). Sayısal analiz yöntemlerinde ise en yaygın uygulanan yöntemler sonlu elemanlar, sonlu farklar, ayrık elemanlar, hibrid yöntemlerdir. Bu yöntemler arasında ise sonlu elemanlar göreceli daha yaygın bir şekilde kullanılmaktadır (Das vd., 2017). Bu çalışmada, sayısal analizlerde sonlu elemanlar yöntemi ile çalışan iki boyutlu Phase ${ }^{2}$ v8.0 (RocScience, 2020) yazılımı kullanılmıştır.

\section{Tünel Destek Sistemlerinin Değerlendirilmesi}

Analitik çözümler (closed form solutions) tünel projelendirme öncesinde genel zemin davranışı ile gerekli olan destek sistemi basınçlarınıbelirlemek amacıyla kullanılmaktadır (Hoek ve Brown, 1980; Hoek, 2007; 2012). Ancak bu yaklaşımda bazı kısıtlamalar ve kabuller vardır. Tünelin hidrostatik koşullar altında olduğu, arazi gerilmelerinin eşit olduğu ve tünelin şeklinin dairesel olduğu varsayılır. Ayrıca zemin homojen ve izotroptur (Hoek, 2007). Arazi koşulları ve tünel geometrisi gerçek durumdan bir miktar uzaklaşmakta ve bu durum analiz sonuçlarını olumsuz etkileyerek sonuçlardaki belirsizliği arttırmaktadır. $\mathrm{Bu}$ nedenle bu tür çözümler mutlaka sayısal analiz yöntemleriyle doğrulanmalıdır. Şekil 12'de dairesel kesiti olan hidrostatik gerilme altında $\mathrm{p}_{0}$ arazi basıncı ve iç destek basıncı $\mathrm{p}_{\mathrm{i}}$, tünel yarıçapı $\mathrm{r}_{0}$ ve plastik zon yarıçap1 $r_{p}$ olarak gösterilmektedir. Çizelge 3'de hidrostatik gerilme ortamı için belirlenen kapalı form eşitlikleri verilmektedir (Hoek ve Brown, 1980; Hoek, 2007; Hoek,2012).

Tünelin fay zonu kesimine ait zemin parametreleri Çizelge 3'te gösterilmektedir. Buradan arazi gerilmesi, $\mathrm{H}=115 \mathrm{~m}, \gamma=19 \mathrm{kN} / \mathrm{m}^{3}$, $\mathrm{r}_{0}=6.5 \mathrm{~m}$, jeostatik basinç $\mathrm{p}_{0}=0.019 \times 115=2.185$ $\mathrm{MPa}$ olarak elde edilir. Tünelde oluşacak birim deformasyon, plastik zon yarıçapı, desteksiz durumda meydana gelen deformasyon, tünel aynasındaki deformasyon hem uzun hem de kısa dönemler için hesaplanmış ve Çizelge 4'de sunulmuştur.

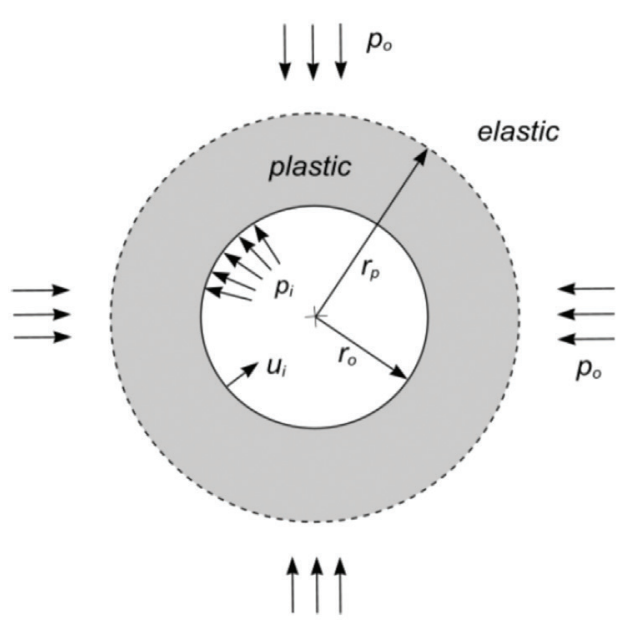

Şekil 12. Dairesel kesitli tünel çevresinde oluşan plastik ve elastik zonlar (Hoek, 2012).

Figure 12. Plastic and elastic zones forming around a circular tunnel (Hoek, 2012).

Desteksiz durumda tünelde meydana gelen deformasyonların kabul edilebilir değerlerin çok üstünde olduğu Çizelge 5'ten anlaşılmaktadır. Şekil 13’ten de görüleceği gibi tünelde oluşacak kapanma/daralma kabul edilebilir seviyede değildir. Tünel desteklerinin hemen kazı sonrasında yapılması gerekmekte olup, çok aşırı sıkışma koşulları içerisinde kazılacağı̆, ayrıca süren ile ayna bulonlarının gerekeceği anlaşılmaktadır. $\left(\frac{\sigma c m}{P o}\right)$ ile yer değiştirme yüzdesi $(\% \mathcal{C})$ arasında Hoek ve Marinos (2000) tarafından önerilen ve Şekil 13'te sunulmuş olan grafik değerlere göre, uzun dönemde tünelde aşırı sıkışmaların meydana geleceği anlaşılmaktadır. Birim yerdeğiştirmelerin $\% 10$ dan büyük olması ve $\left(\frac{\sigma c m}{P o}\right)$ oranının uzun dönem için 0.04 mertebesinde olması nedeniyle tünelde uzun dönemde aşırı sıkışmalar beklenmektedir. 
Çizelge 3. Kapalı form eşitlikleri (Hoek ve Brown, 1980; Hoek, 2007; Hoek, 2012).

Table 3. Closed form equations (Hoek ve Brown, 1980; Hoek, 2007; Hoek, 2012).

\begin{tabular}{|c|c|c|c|}
\hline $\begin{array}{l}\text { Mohr Coulomb } \\
\text { yenilme kriteri (1) }\end{array}$ & $\sigma_{1}^{\prime}=\sigma_{c m}+k \sigma_{3}^{\prime}$ & $\begin{array}{l}\text { Plastik zon } \\
\text { yarıçapı rp (pi=0) } \\
(6)\end{array}$ & $r p=r o\left[\left(\frac{2(p 0(k-1)+\sigma c m)}{(1+k)((k-1) p i+\sigma c m)}\right] \wedge \frac{1}{k-1}\right.$ \\
\hline $\begin{array}{l}\text { Kaya kütlesinin } \\
\text { tek eksenli yenilme } \\
\text { dayanımı } \sigma_{\mathrm{cm}}(2)\end{array}$ & $\sigma_{c m}=\frac{2 c^{\prime} \cos \phi^{\prime}}{\left(1-\sin \phi^{\prime}\right)}$ & $\begin{array}{l}\text { Plastik } \\
\text { yerdeğiştirme } \\
\text { uip (7) }\end{array}$ & $\begin{aligned} u i p=\left(\frac{r o(1+\vartheta)}{E m}\right) & {\left[2(1-\vartheta)(p 0-p c r)\left(\frac{r p}{r 0}\right)^{2}\right.} \\
& -(1-2 \vartheta)(p 0-p i)]\end{aligned}$ \\
\hline k (3) & $k=\frac{\left(1+\sin \phi^{\prime}\right)}{\left(1-\sin \phi^{\prime}\right)}$ & $\begin{array}{l}\text { \%Deformasyon, } \\
\varepsilon(8)\end{array}$ & $\varepsilon \%=\left(\frac{u i}{r o}\right) x 100=\left[0.2-0.25\left(\frac{p i}{p 0}\right)\left(\frac{\sigma c m}{p 0}\right)^{2.4\left(\frac{p i}{p 0}\right)-2}\right)$ \\
\hline $\begin{array}{l}\text { Kritik tahkimat basinc1 } \\
p_{c r}(4)\end{array}$ & $P c r=\frac{2 p 0-\sigma c m}{1+k}$ & $\begin{array}{l}\text { Plastik zon } \\
\text { yarıçapı (9) }\end{array}$ & $\left(\frac{r p}{r 0}\right)=\left(1.25-0.625\left(\frac{p i}{p 0}\right)\left(\frac{\sigma c m}{p 0}\right)^{\left(\frac{p i}{p o}\right)-0.57}\right)$ \\
\hline $\begin{array}{l}\text { Elastic yerdeğiştirme } \\
\text { uie (5) }\end{array}$ & \multicolumn{3}{|c|}{ uie $=\frac{r 0(1+\vartheta)(p 0-p i)}{E m}$} \\
\hline \multicolumn{3}{|c|}{$\begin{array}{l}r p=\text { Plastik zon yarıçapı } \\
u_{i}=\text { Yerdeğiştirme } \\
r O=\text { Tünel yarıçapı } \\
p i=\text { Tahkimat basıncı } \\
p o=\text { Arazi gerilmesi } \\
\sigma_{c m}=\text { Kaya kütle dayanmı } \\
E m=\text { Deformasyon modülü }\end{array}$} & 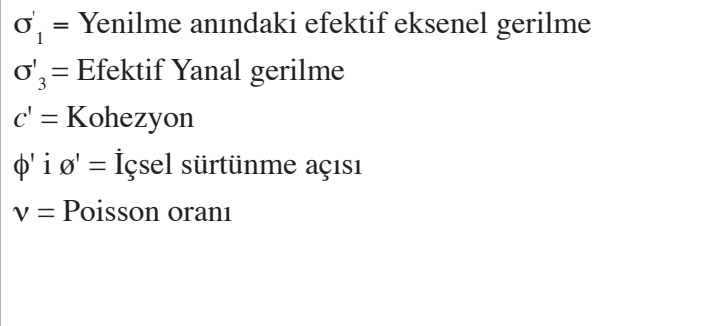 \\
\hline
\end{tabular}

Çizelge 4 Kapalı form eşitliklerine göre kısa ve uzun dönem parametreleri kullanılarak hesaplanan değerler. Table 4. Calculated values using short- and long-term parameters according to the closed form equations.

\begin{tabular}{ccccccccc}
\hline & $\sigma_{\mathrm{cm}}$ & $\mathrm{P}_{0}$ & $\sigma_{\mathrm{cm}} / \mathrm{P}_{0}$ & $\mathrm{r}_{\mathrm{p}}(\mathrm{m})$ & $\varepsilon(\%)$ & $\mathrm{u}_{\mathrm{i}}(\mathrm{m})$ & $\mathrm{u}_{\mathrm{if}}(\mathrm{m})$ & $\mathrm{P}_{\mathrm{cr}}(\mathrm{MPa})$ \\
\hline $\begin{array}{c}\text { Kisa Dönem } \\
\text { Parametreleri }\end{array}$ & 0.54 & 2.185 & 0.25 & 25.27 & 43.4 & 2.82 & 0.52 & 1.35 \\
\hline $\begin{array}{c}\text { Uzun Dönem } \\
\text { Parametreleri }\end{array}$ & 0.08 & 2.185 & 0.04 & 40.23 & 145 & 9.35 & 1.23 & 1.14 \\
\hline
\end{tabular}


Aygar, Gokceoglu

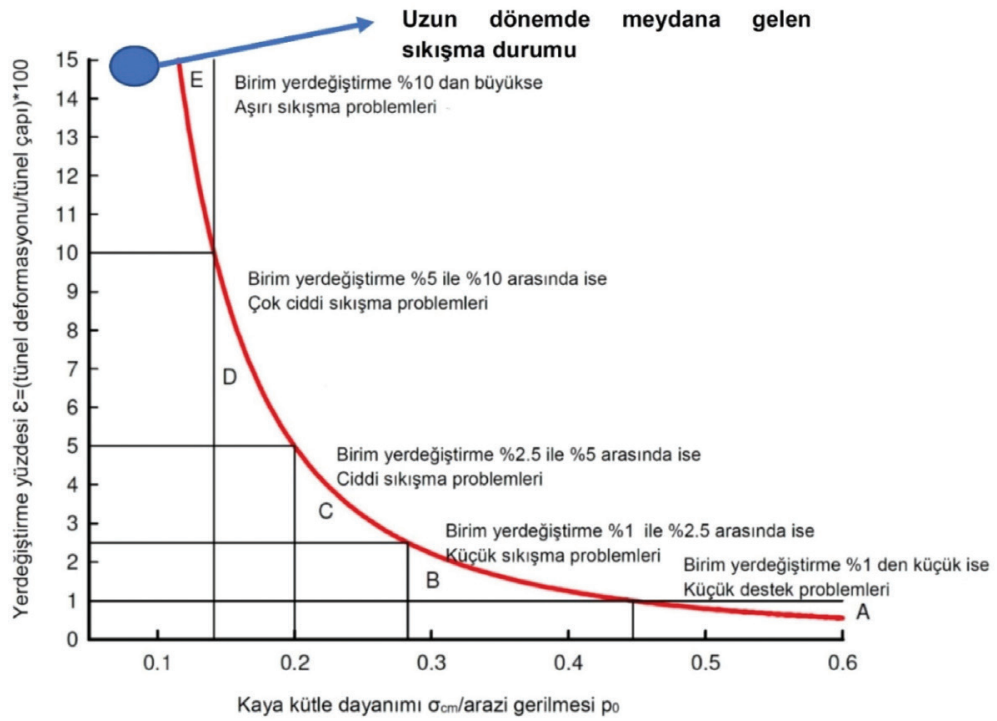

Şekil 13. Desteksiz tünellerde birim yerdeğişirmeye bağlı olarak meydana gelen sıkışma problemlerinin derecesini tahmin abăg 1 (Hoek ve Marinos, 2000).

Figure 13. Degree of squeezing problems estimation chart for unsupported tunnels depending on unit displacement (Hoek and Marinos, 2000).

\section{Kaya Destek İlişkisi Analizi-Kaya ve Destek Eğrileri}

İlgili literatürde tünel destek sistemlerinin ve tünel davranışının belirlemek amacıyla zemin reaksiyon eğrisi "Grolund Response Curve" (GRC), destek reaksiyon eğrisi "Support Reaction Curve" (SRC), boyuna deformasyon profili "Longitudinal Deformation Profile" (LDP) üzerinde çalışmalar gerçekleştirilmiştir (Hoek ve Brown, 1980; Unlu ve Gercek, 2003; Hoek vd., 2008; Vlachopoulos ve Diedrichs, 2009). Yukarıda belirtilen çalışmalarda destek sistemlerinin optimizasyonu (en iyileme) için

$$
u_{i}= \begin{cases}u_{i m} \cdot\left[\frac{u_{i f}}{u_{i m}} \cdot e^{x / r_{0}}\right] & , x<0 \\ u_{i m} \cdot\left[\left(\frac{u_{i m}}{3}\right) e^{-0.15\left(r_{p m} / r_{0}\right)}\right] & , x=0 \\ u_{i m} \cdot\left[1-\left(1-\frac{u_{i f}}{u_{i m}}\right) \cdot e^{\left(-3 x / r_{0}\right) /\left(2 r_{p m} / r_{0}\right)}\right] & , x>0\end{cases}
$$

hangi durum ve yer değiştirmeler altında destek sistemlerinin yerleştirileceği araştırılmıştır. Çalışma kapsamında, fay zonu kesimi için hem kisa hem de uzun dönem parametrelerine göre zemin reaksiyon eğrisi, destek reaksiyon eğrisi ile boyuna yerdeğiştirme profili hem kısa hem de uzun dönem parametreleri kullanılarak elde edilmiştir. Zemin reaksiyon eğrisinin tespit edilmesi sırasında Eşitlik 4 - 7 kullanılmış ve plastik zon yarıçapının tespitinde ise Eşitlik 6 kullanılmıştır. Boyuna deformasyon profili çizdirilirken Vlachopoulos ve Diederichs (2009) tarafından önerilen Eşitlik 10 kullanılmıştır. 
Burada $u_{i f}$, tünel aynasındaki deformasyonu, $\mathrm{u}_{\mathrm{im}}$ maksimum yerdeğiştirmeyi göstermektedir. Tünel destek sistemlerinin destek basınçlarının hesaplanmasında Çizelge 5'te verilen eşitlikler kullanılmıştır. Bununla birlikte fay zonundaki kesimi için seçilen destek sistemi özeti Çizelge 6'da verilmektedir.

Çizelge 5. Destek kapasitesi eşitlikleri (Hoek ve Brown, 1980; Brady ve Brown, 1985).

Table 5. The equations of support capacity (Hoek ve Brown, 1980; Brady ve Brown, 1985).

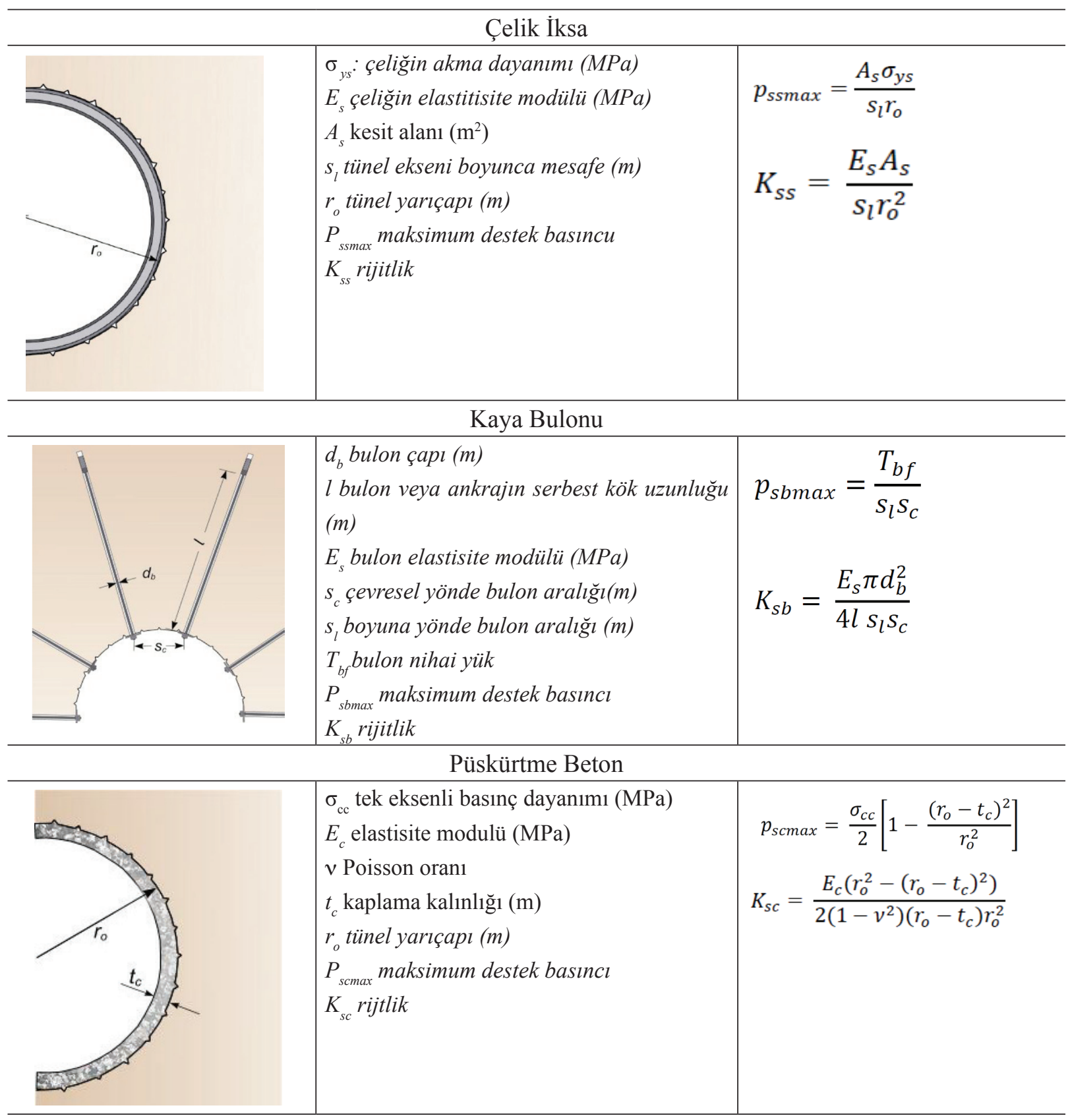


Çizelge 6. Tünel destek sistemi detayları.

Table 6. Details of tunnel support systems.

\begin{tabular}{cc}
\hline Destek elemanı & Özellik \\
\hline Püskürtme beton & $45 \mathrm{~cm}$ \\
C20/25 & I 200 \\
Çelik İksa & $12 \mathrm{~m}, \mathrm{~d}=32 \mathrm{~mm}$ \\
Kaya bulonu & Pult=280 kN \\
Süren & $12 \mathrm{~m}, 3.5$ veya 4", $6 \mathrm{~m}$ \\
bindirme \\
Round Mesafesi & $1 / 2 / 4 \mathrm{~m}$ \\
Üst yar1/Alt yarı/Invert & 2 kat \\
Hasır Çelik, Q589/443 & $10 \mathrm{~cm}$ püskürtme \\
Ayna Desteği & beton/1 kat hasır çelik \\
& $9 \mathrm{~m}$ ayna bulonu \\
\hline
\end{tabular}

\section{Kısa Dönem Parametrelerine Göre Analizler}

Tünelin fay zonu bölgesi için, Şekil 14'de zemin reaksion eğrisi, Şekil 15 'te boyuna yerdeğiştirme profili ve Şekil 16 'da da destek reaksiyon eğrisi sunulmaktadır. Tünel destek sistemi basınçları ve rijitlik değerleri ise Çizelge 7'de verilmektedir.

Çizelge 7. Fay zonu destek sistemi basınçları.

Table 7. Support systems pressures in the fault zone.

\begin{tabular}{ccc}
\hline Destek Elemanı & $p_{\text {scmax }}(M P a)$ & $K_{s c}(M P a / m)$ \\
\hline Püskürtme Beton & 2.00 & 327.96 \\
Çelik İksa & 0.187 & 16.36 \\
Kaya Bulonu & 0.28 & 13.875 \\
\hline
\end{tabular}

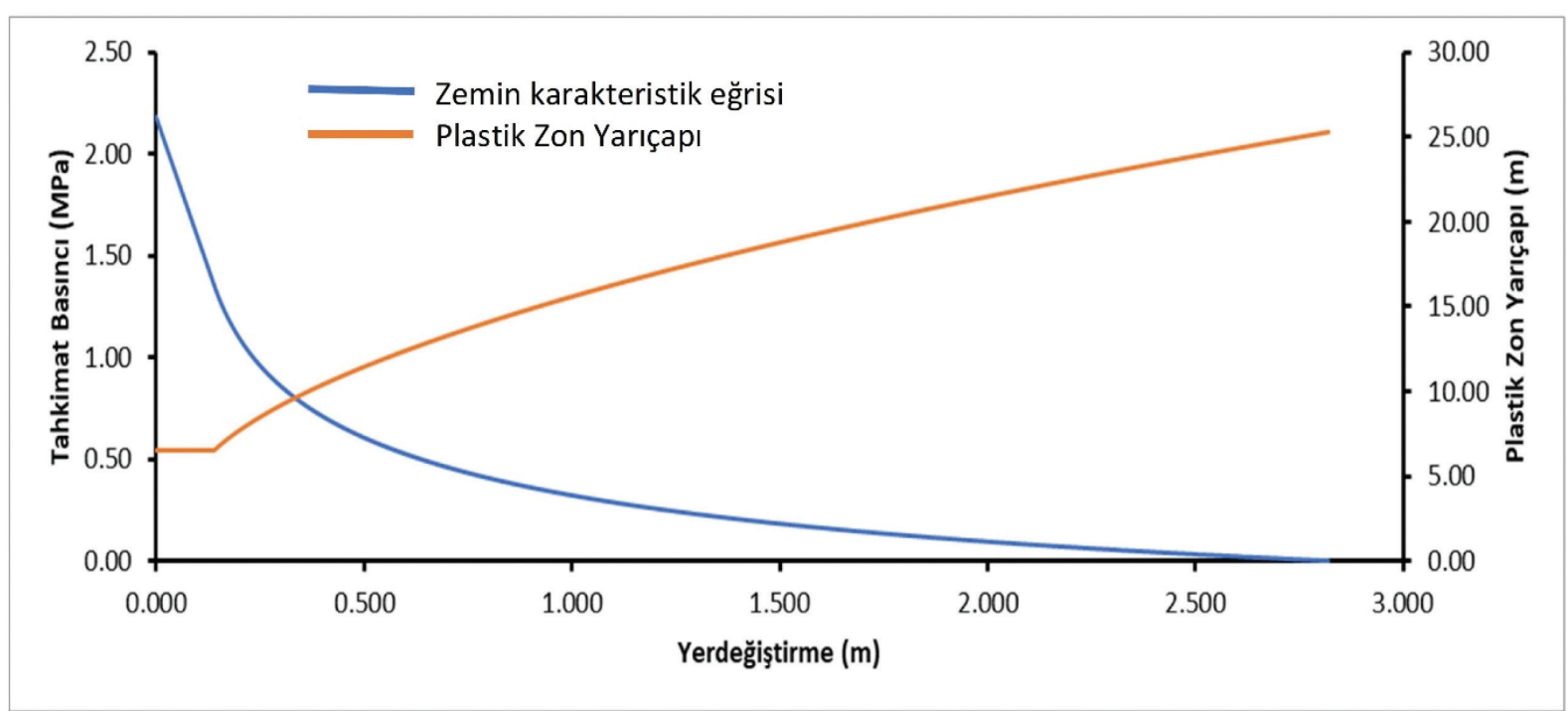

Şekil 14. Fay zonu bölgesi için kısa dönem parametreleri kullanılarak elde edilen zemin tepki eğrisi ve plastik zon yarıçapı.

Figure 14. Ground reaction curve and plastic zone's radius obtained by using short-term parameters for the fault zone. 


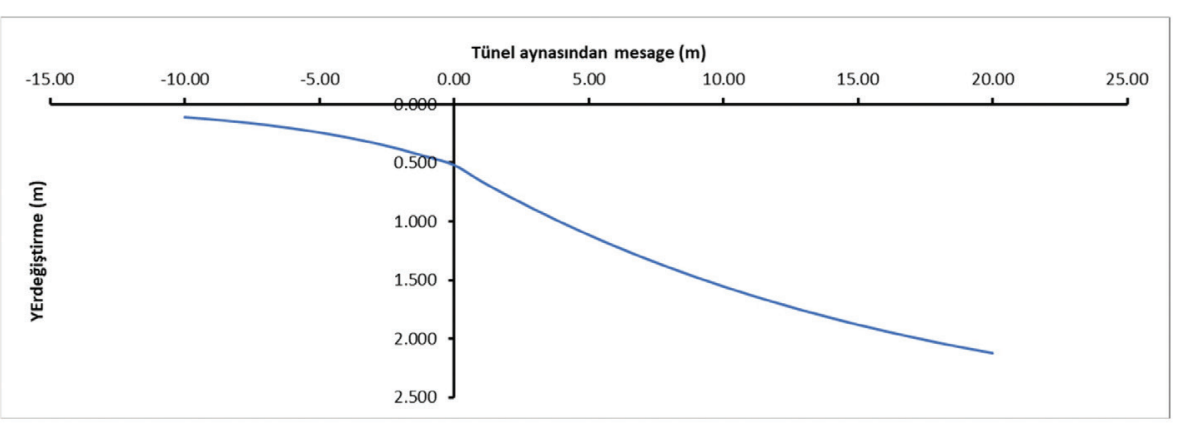

Şekil 15. Kısa dönem parametreleri kullanılarak elde edilen boyuna deformasyon eğrisi.

Figure 15. Longitudinal deformation profile obtained using short term parameters.

Yapılan analizlerde, $\mathrm{r}_{\mathrm{pm}} / \mathrm{r}_{0}=3.89$ olarak hesaplanmıştır. Kısa dönemde tünel çevresindeki plastik zon yarıçapı 25 m’ye kadar çıkmaktadır (Şekil 15). Aynı şekilde kısa dönem için tünel aynasında meydana gelen yerdeğiştirme ise $\mathrm{u}_{\mathrm{if}}=0.52 \mathrm{~m}$ olarak hesaplanmıştır. Tünel aynasının
$1 \mathrm{~m}$ gerisinden, desteklerin yapılması durumunda $65 \mathrm{~cm}$ düzeyinde deformasyon olmaktadır (Şekil 16). Ayrıca, Şekil $17^{\prime}$ de verilen eğriye göre de, tünelde deformasyonların gelişmesine izin vermeyecek şekilde yerleştirilmesi gerektiği açık bir şekilde görülmektedir.

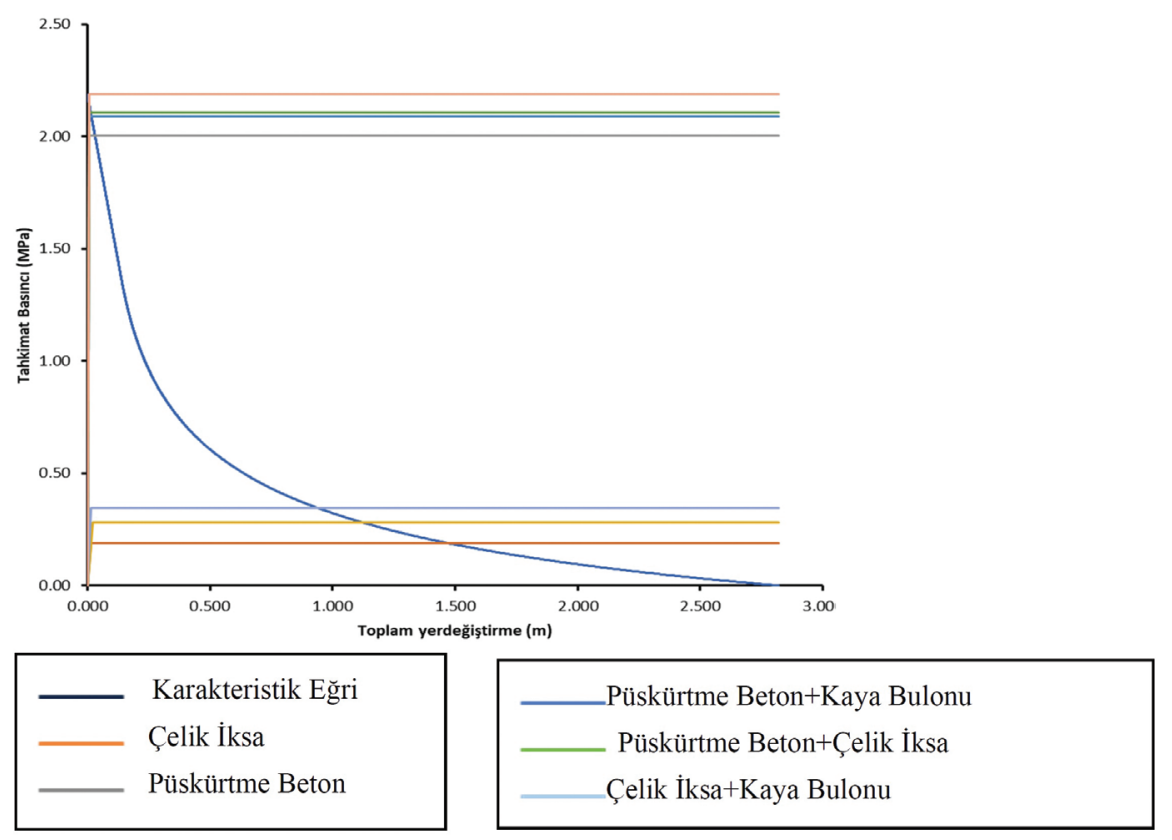

Şekil 16. Kısa dönem parametreleri kullanılarak elde edilen zemin ve destek sistemi karakteristik eğrisi.

Figure 16. Ground and support system characteristic curve obtained using short-term parameters. 
Aygar, Gokceoglu

\section{Uzun Dönem Parametrelerine Göre Analizler}

Tünelin fay zonu bölgesi için uzun dönem parametrelerine göre, Şekil 17'de zemin reaksiyon eğrisi, Şekil 18'de boyuna yerdeğiştirme profili ve Şekil 19'da da destek reaksiyon eğrisi sunulmuştur.

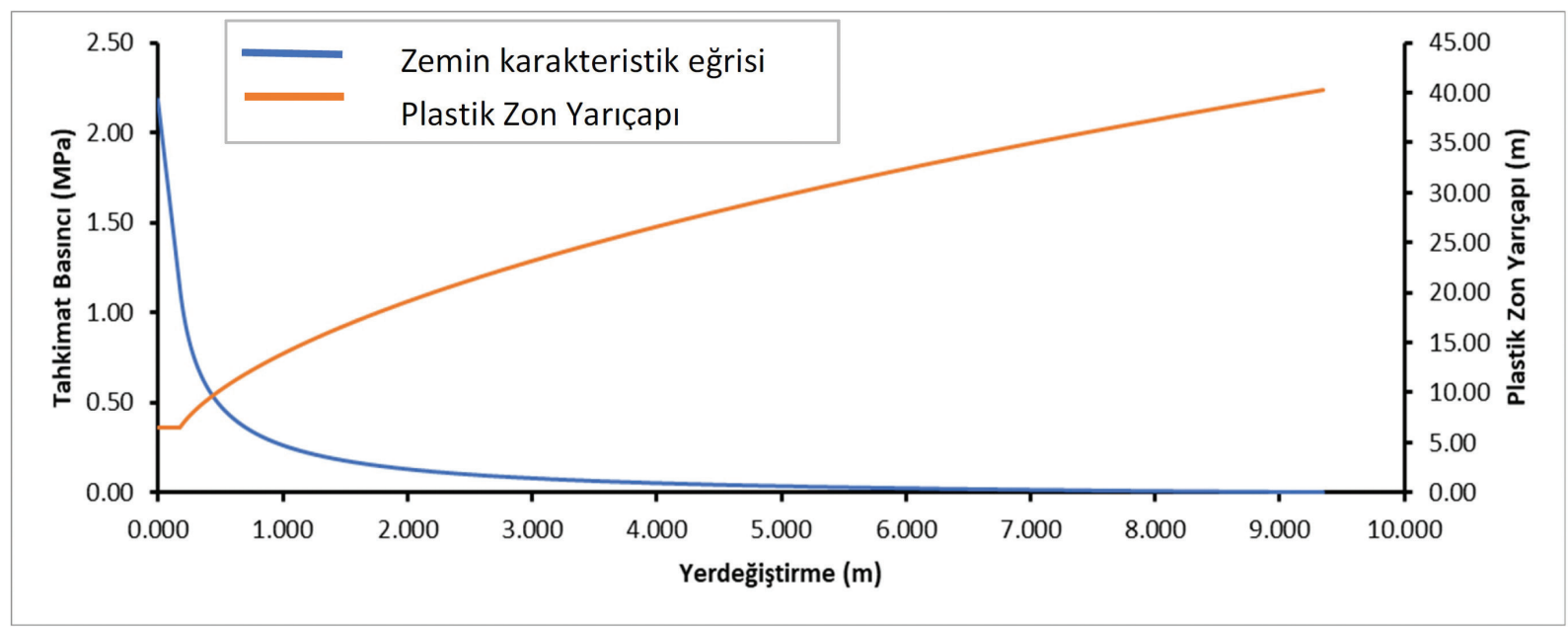

Şekil 17. Fay zonu bölgesi için uzun dönem parametreleri kullanılarak hesaplanan zemin tepki eğrisi ve plastik zon yarıçapı.

Figure 17. Ground reaction curve and plastic zone radius obtained using long-term parameters for the fault zone.

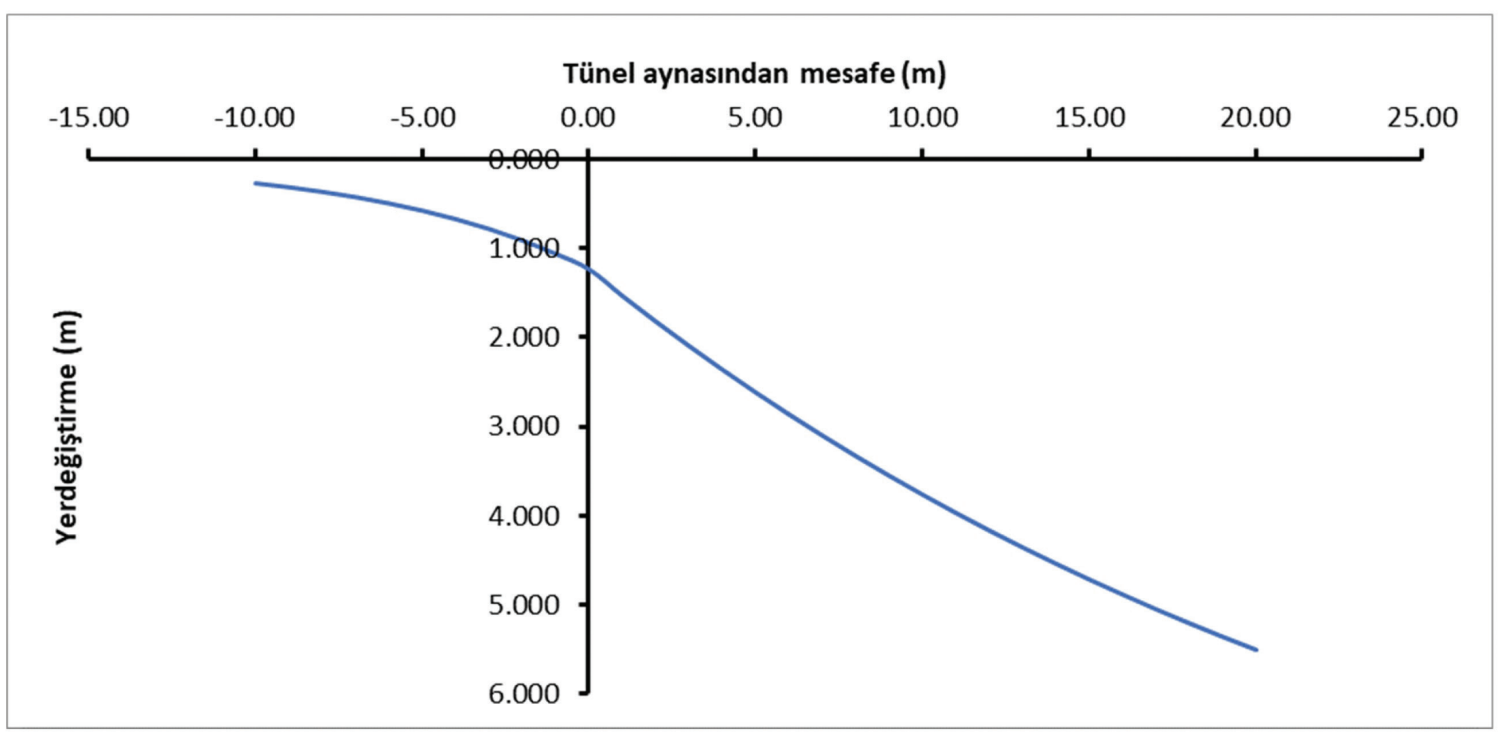

Şekil 18. Uzun dönem parametreleri kullanılarak hazırlanan boyuna deformasyon eğrisi.

Figure 18. Longitudinal deformation profile obtained using the long-term parameters. 
Uzun dönem parametreler kullanılarak yapilan analizlerde, $\quad \mathrm{r}_{\mathrm{pm}} / \mathrm{r}_{0}=6.19$ olarak hesaplanmış olup, tünel çevresindeki plastik zon yarıçapı 40.23 m'ye kadar çıkmaktadır (Şekil 17). Aynı şekilde tünel aynasında meydana gelen yerdeğiştirme ise $u_{i f}=1.23 \mathrm{~m}$ dir. Tünel aynasının $1 \mathrm{~m}$ gerisinden, desteklerin yapılması durumunda ise $1.25 \mathrm{~m}$ düzeyinde deformasyon olmaktadır (Şekil 18). Ayrıca seçilen destek elemanları ile zemin reaksiyon eğrisi ve destek sistemi reaksiyon eğrisi Şekil 19'da verilmektedir. Elde edilen sonuçlara göre, deformasyona izin verilmeden tahkimatların yerleştirilmesi gerekmektedir.
$\mathrm{Bu}$ bölümde gerçekleştirilen tüm analizler birlikte incelendiğinde, hem kısa dönem hem de uzun dönem analizleri sonuçları tünelde ön destekleme hem tünel aynasında hem de tünel tavanında zorunlu olduğunu göstermiştir. $\mathrm{Bu}$ durumda öncelikle tünelde herhangi bir deformasyona izin verilmeden tünel desteklerinin yapılması gerektiği ortaya çıkmaktadır. Buna ek olarak tünel aynasında ve tavanında yapılacak olan destekler güvenlik faktörünü arttıracaktır. Sonuç olarak tünelde herhangi bir deformasyona izin verilmesi halinde, önce deformasyonlar çok hızlı ve yüksek değerlerde gerçekleşecek ve sonuçta yenilme kaçınılmaz olacaktır.

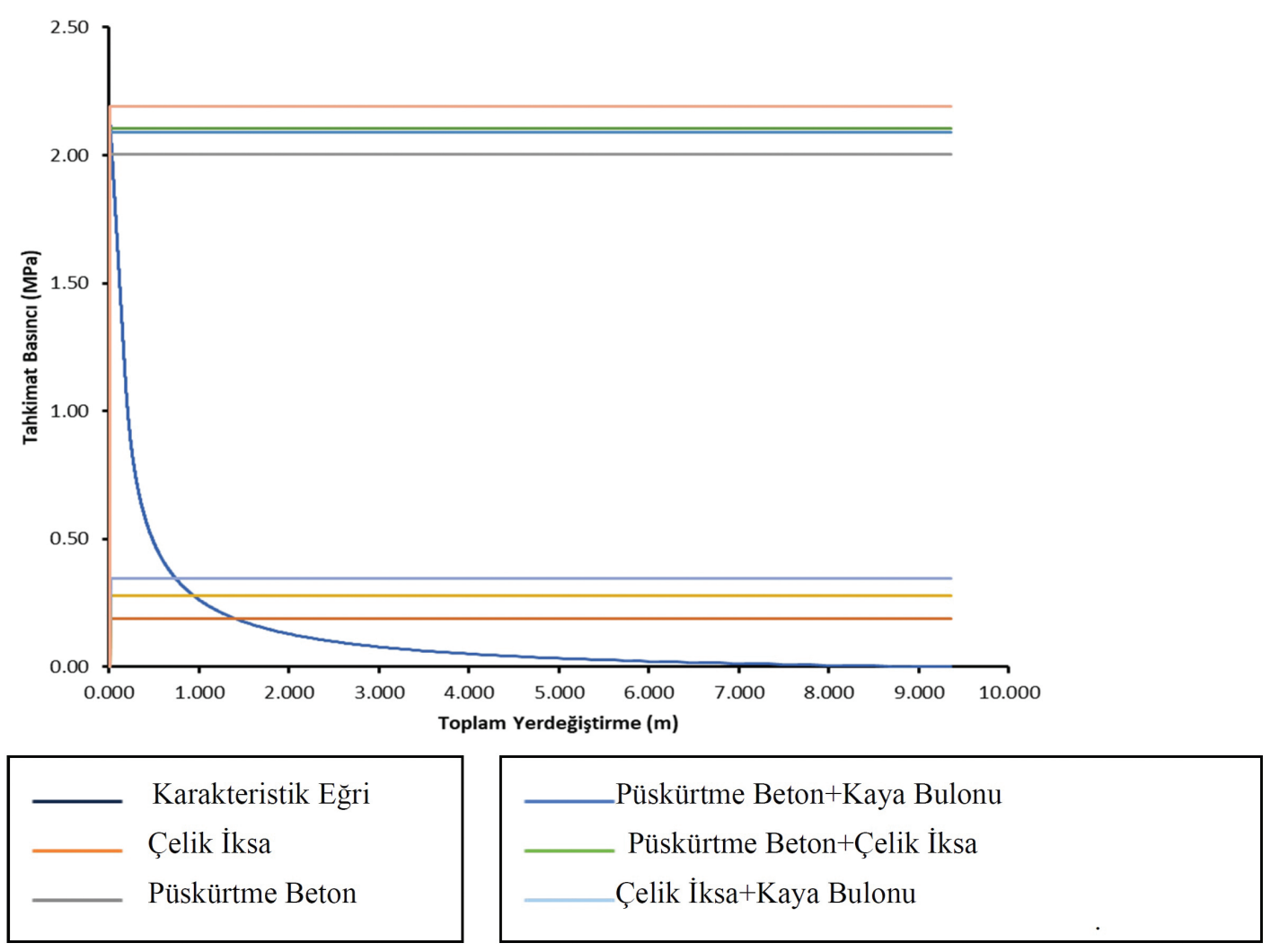

Şekil 19. Uzun dönem parametreleri kullanılarak hazırlanan zemin ve destek sistemi karakteristik eğrisi.

Figure 19. Characteristic curve of the ground and support system obtained using the long-term parameters. 
Aygar, Gokceoglu

\section{Sayısal Analizler}

Fay zonu kesiminin modellenmesi için, öncelikle mevcut durumda kullanılan destek sistemleri ile tünel modeli hazırlanarak analizler gerçekleştirilmiştir. Kazı aşamasında bu kesim C2 destek sistemi ile geçilmiştir. C2 destek sistemi I200 tipi çelik iksayı, $30 \mathrm{~cm}$ püskürtme betonu ve $8 \mathrm{~m}$ kaya bulonunu kapsamaktadır. Çalışmada dikkate alınan modelleme aşamaları Çizelge 8'de verilmektedir. Toplam dokuz aşamada mevcut durum ve tarama sonrası durum modellenmiş olup, oluşturulan geometrik model ve aşamaları ise Şekil 20 ve 21 'de sunulmuştur. 7. aşamada verilen modelde deformasyonlar sıfırlanmış ve tarama kazısına bu aşamada başlanmıştır. Buna ek olarak, bu aşamada modelde $\mathrm{C} 2$ kaya sınıfında yerleştirilen bulonlar ile çelik iksa ve $30 \mathrm{~cm}$ püskürtme beton modelden kaldırılmıştır (Şekil 22). 8. aşamada kullanılan modelde tarama kazısında kullanılan yeni destek sistemleri tanımlanmıştır. Tünelin bu kesiminde, modelde sabit gerilmeler uygulanmıştır. Burada düşey gravityasyon gerilmesi $\sigma \mathrm{v}=\mathrm{h}^{*} \gamma$ (Fenner, 1938) eşitliği ile, yatay gerilmeler ise bu kesimin fay zonu olması sebebiyle düşey gerilmeye eşit alınmıştır $\left(\sigma_{\mathrm{v}}=\sigma_{\mathrm{h}}\right)$. Buna göre ortamdaki düşey ve yatay gerilmeler $2.18 \mathrm{MPa} \approx 2.2$ $\mathrm{MPa}$ olarak hesaplanmış ve modellemede sabit öngörülmüşsür.

Çizelge 8. Modelleme aşamaları.

Table 8. Modelling stages.

\begin{tabular}{|c|c|c|}
\hline 1 & \multicolumn{2}{|c|}{ Arazi Gerilmelerinin Oluşturulması } \\
\hline 2 & $\begin{array}{l}\text { Üst yarı kazısı, bulon, iksa ve püskütme beton } \\
\text { yerleştirilmesi }\end{array}$ & $\begin{array}{c}8 \mathrm{~m} \text { IBO bulon }(1.2 \times 1.0 \mathrm{~m}) \\
\text { I } 200 \mathrm{iksa}, 30 \mathrm{~cm} \text { püskütme beton }(\mathrm{C} 20 / 25)\end{array}$ \\
\hline 3 & $\begin{array}{l}\text { Alt yarı kazısı, bulon, iksa ve püskütme beton } \\
\text { yerleştirilmesi }\end{array}$ & $\begin{array}{c}8 \mathrm{~m} \text { IBO bulon }(1.2 \times 1.0 \mathrm{~m}) \\
\text { I } 200 \mathrm{iksa}, 30 \mathrm{~cm} \text { püskütme beton }(\mathrm{C} 20 / 25)\end{array}$ \\
\hline 4 & $\begin{array}{l}\text { Invert kazısı, bulon, iksa ve püskütme beton } \\
\text { yerleştirilmesi }\end{array}$ & $\begin{array}{c}8 \mathrm{~m} \text { IBO bulon }(1.2 \times 1.0 \mathrm{~m}) \\
\text { I } 200 \mathrm{iksa}, 30 \mathrm{~cm} \text { püskütme beton }(\mathrm{C} 20 / 25)\end{array}$ \\
\hline 6 & Invert Betonu yerleştirilmesi & - \\
\hline 7 & $\begin{array}{l}\text { Alt yarının malzeme ile doldurulması ve } \\
\text { deformasyonların sıfirlanması }\end{array}$ & - \\
\hline 8 & Üst yarı tarama kazısı & $\begin{array}{c}12 \mathrm{~m} \text { IBO bulon }(1.0 \times 1.0 \mathrm{~m}) \\
\text { I } 200 \mathrm{iksa}, 45 \mathrm{~cm} \text { püskütme beton }(\mathrm{C} 30 / 37)\end{array}$ \\
\hline 9 & Alt yarı tarama kazısı & $\begin{array}{c}12 \mathrm{~m} \text { IBO bulon }(1.0 \times 1.0 \mathrm{~m}) \\
\text { I } 200 \mathrm{iksa}, 45 \mathrm{~cm} \text { püskütme beton }(\mathrm{C} 30 / 37)\end{array}$ \\
\hline
\end{tabular}




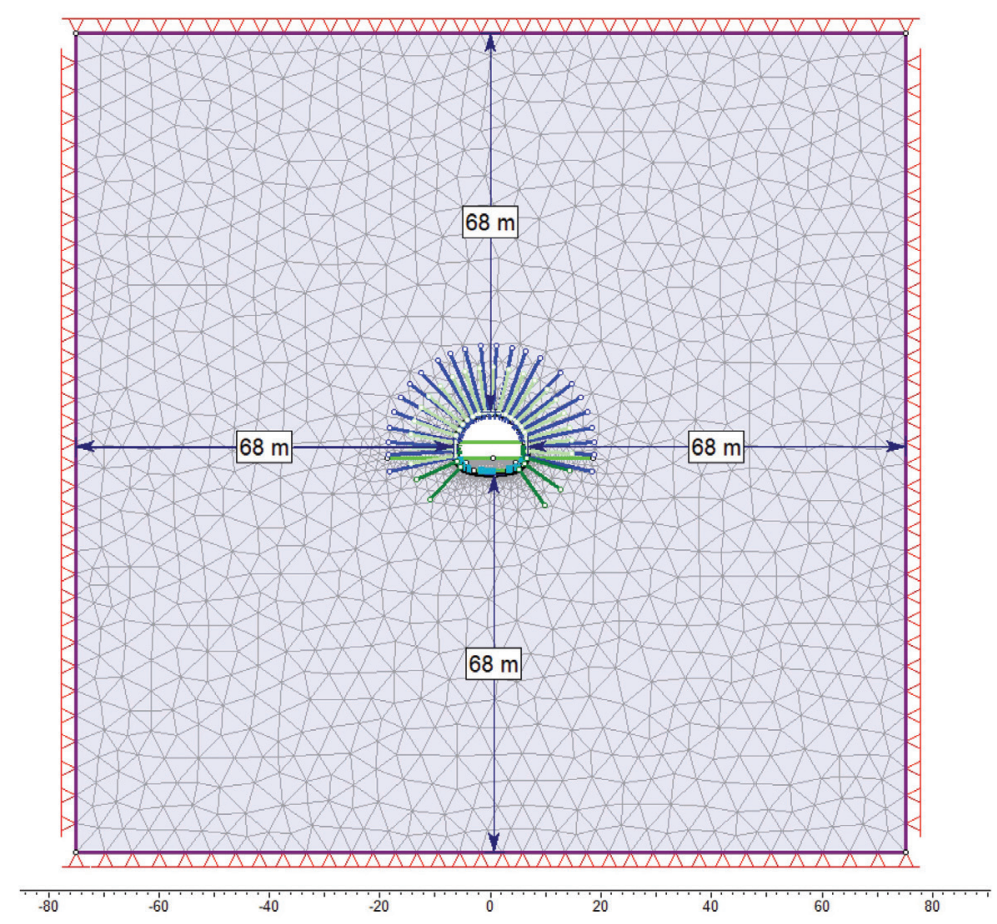

Şekil 20. Phase2d programı ile oluşturulan modelin sınır koşulları.

Figure 20. Model boundary conditions created by the Phase2d software.

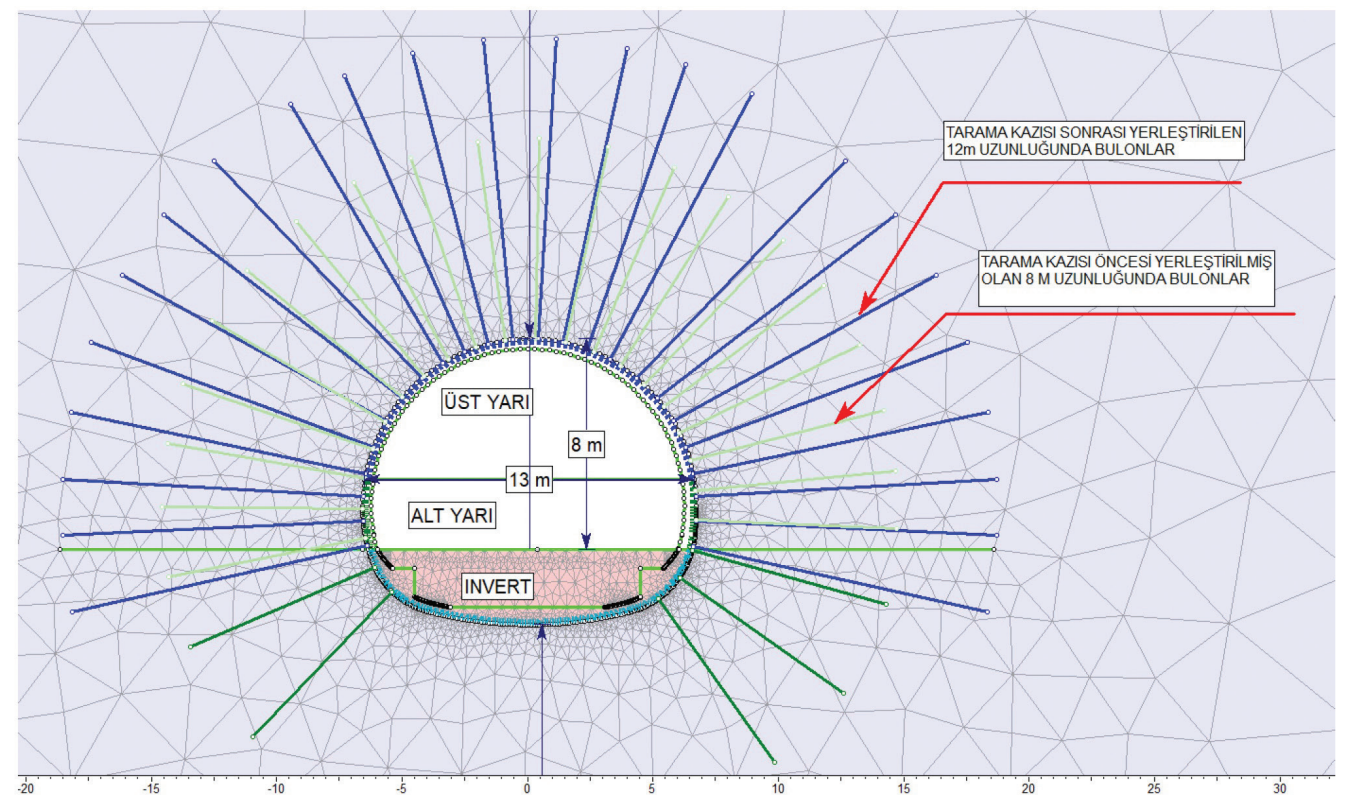

Şekil 21. Phase2d programı ile oluşturulan model destekleme sistemi detayları.

Figure 21. Details of the model supporting system created by the Phase2d software. 

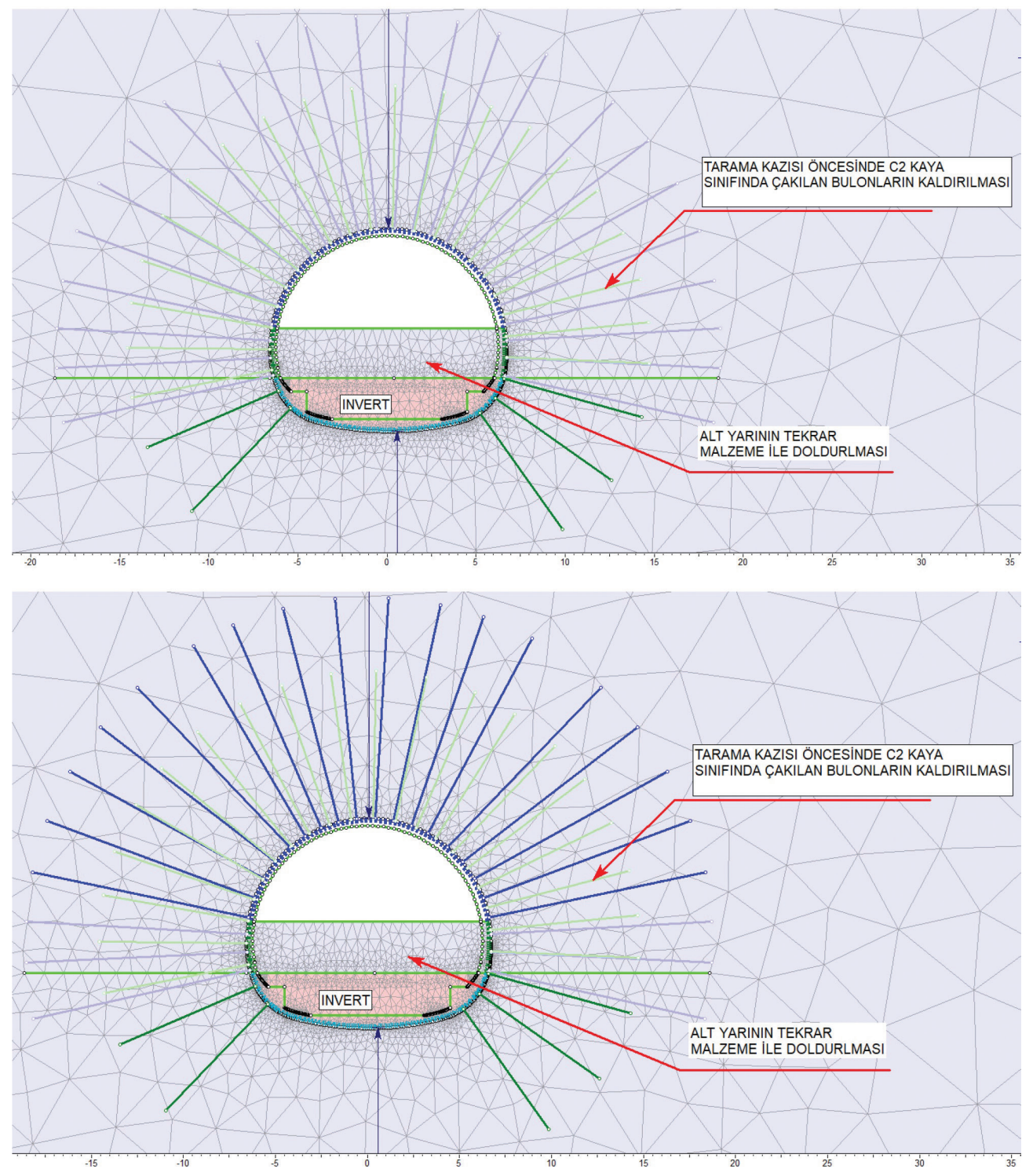

Şekil 22. Tarama kazısı öncesinde alt yarı kesiminin malzeme ile doldurulması ve bulonların kaldırılması (aşama 7 ve 8 ).

Figure 22. Filling the bench section with material and removing bolts before the re-profiling excavation (stages 7 and 8).

\section{Analiz Sonuçlarının Değerlendirilmesi}

Tünelde C2 destek sınıfi ile kazısı yapılan kesimin modellenmesi ilk 6 aşamada tamamlanmıştır. Başlangıçta mevcut durumun deformasyon ve gerilme durumları verilmekte, daha sonra da tarama kazısı sonucunda oluşan durum incelenmektedir. Tünelde C2 kaya sınıfi ile yapılan analizlerde tünel çevresinde $50 \mathrm{~cm}$ 'yi aşan deformasyolar gözlenmiş ve (Şekil 23) tünelin bu kesimde yenileceği ortaya çıkmıştır. 
Tünelde yapılan deformasyon okumalarında da deformasyonların $50 \mathrm{~cm}$ 'i aştığı kesimlerin varlığ 1 ortaya çıkmıştır. Tünel çevresindeki yenilmeler Şekil 24'de verilmekte olup, yenilmelerin tünel çevresinde 12 m'yi aşan bir kesimde yeraldığı gözlenmiştir. Şekil 25'de ise tünelde meydana gelen $\sigma_{1}$ değerlerinin dağılımı görülmektedir. Ortamdaki kaya kütlesinin uzun dönemdeki kaya kütle dayanımı $\sigma_{\mathrm{cm}}=0.08 \mathrm{MPa}$ olduğu dikkate alındığında, güvenlik katsayısı 0.1 olarak elde edilmektedir.

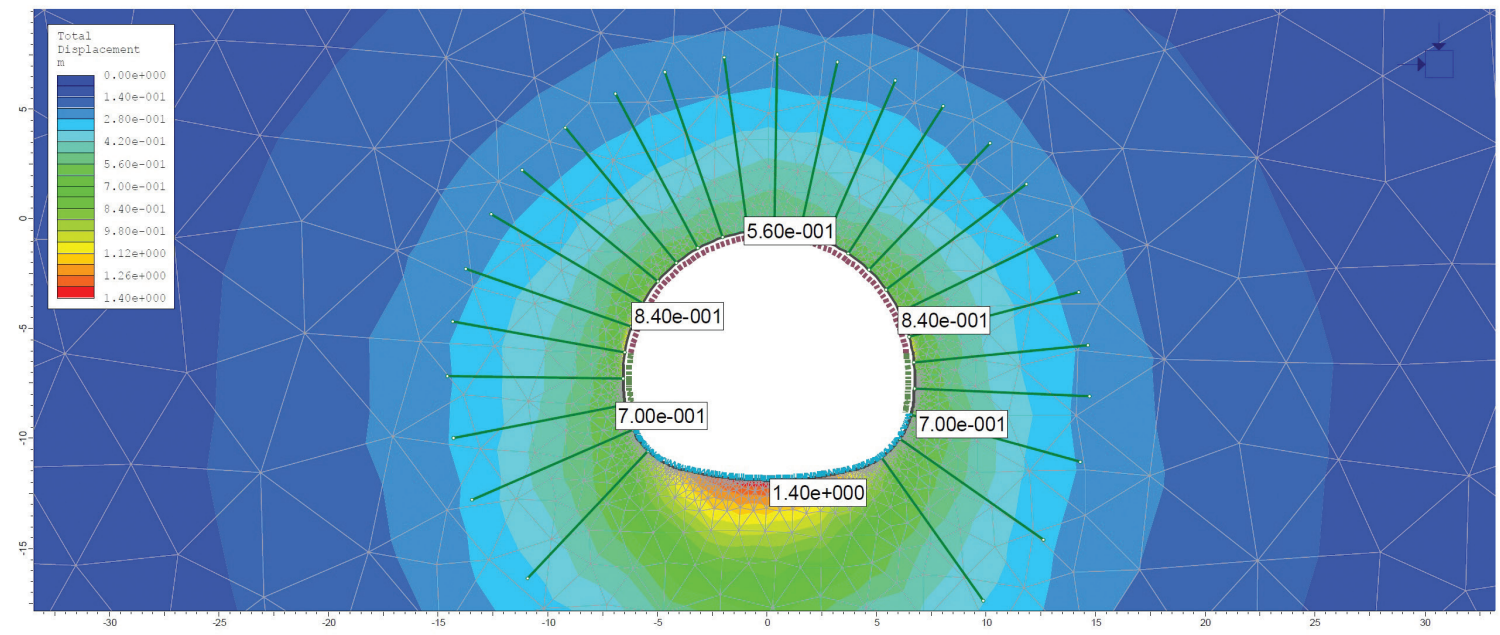

Şekil 23. C2 kaya sınıfında meydana gelen toplam yerdeğiştirmeler.

Figure 23. Total displacements for the C2 rock support class.

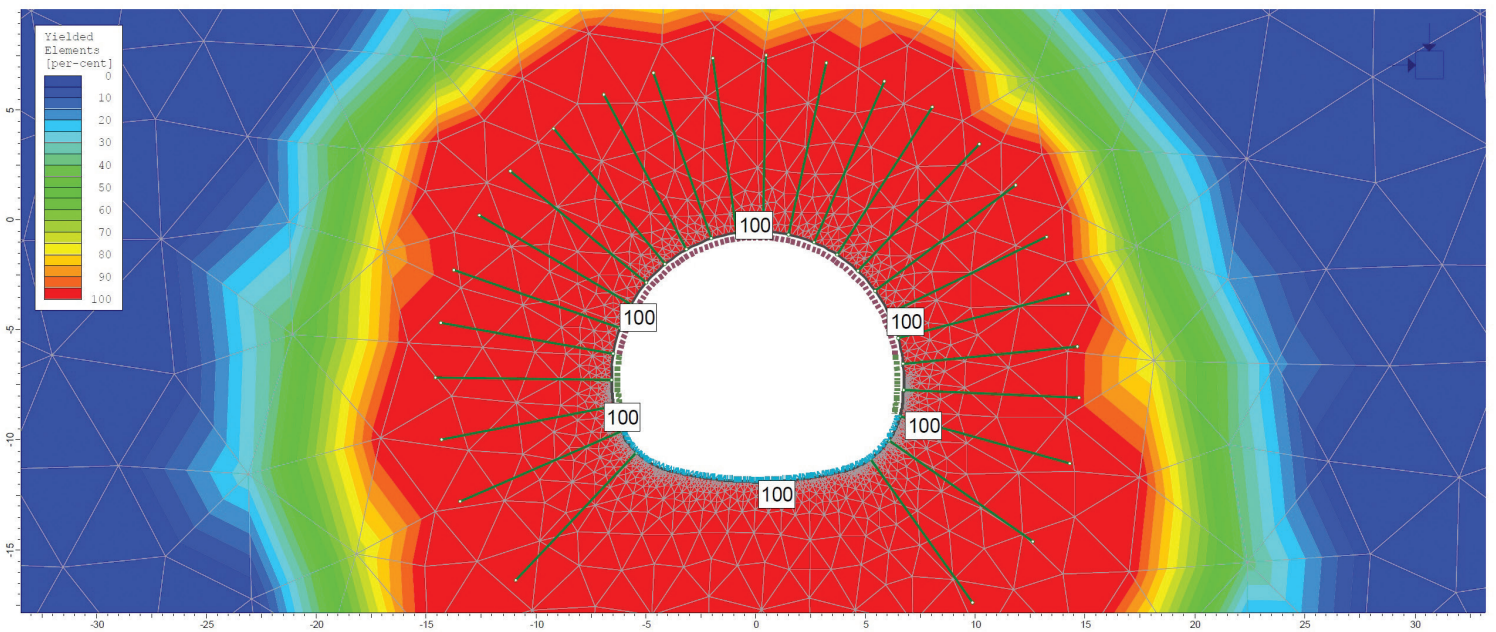

Şekil 24. C2 kaya sınıfinda meydana gelen yenilme zonu.

Figure 24. Failure zone occured in the C2 rock support class. 


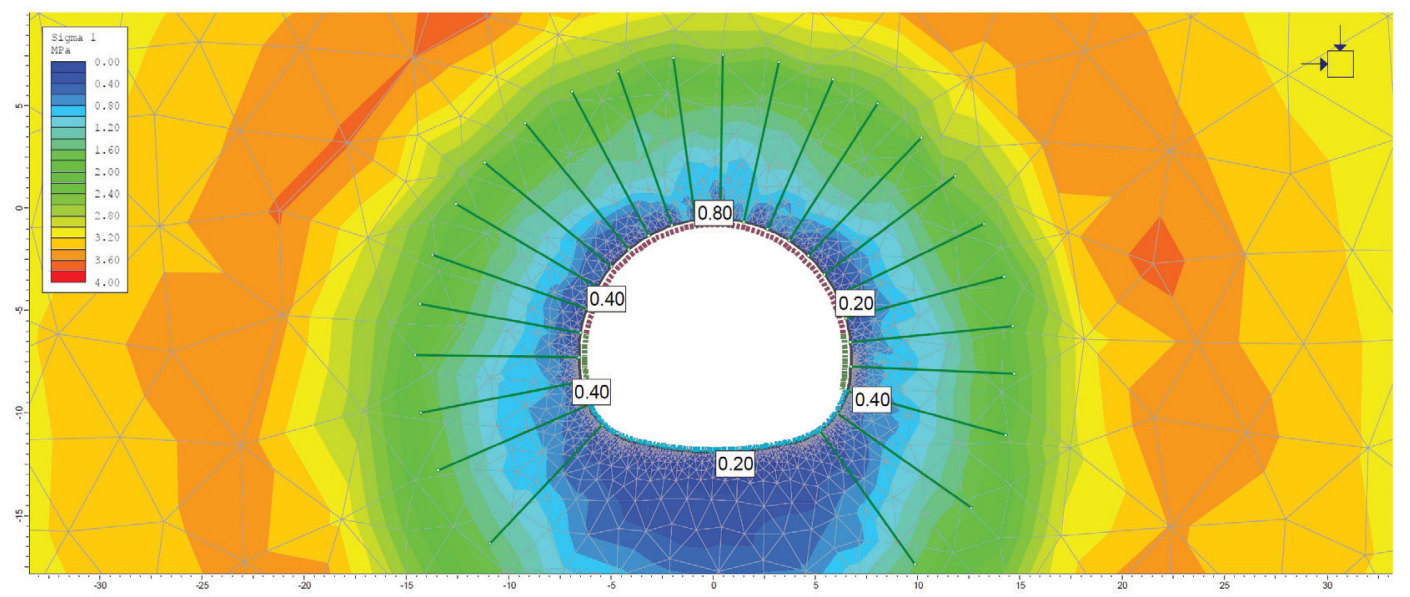

Şekil 25. C2 kaya sınıfında meydana gelen $\sigma_{1}$ gerilme değerleri.

Figure 25. $\sigma_{1}$ vertical stress values occured in the C2 rock support class.

$\mathrm{Bu}$ aşamadan sonra modelde, üst yarıda tarama kazısı ve destekleri ile alt yarıda tarama kazısı ve destekleri yerleştirilerek model analize tabi tutulmuş ve son aşamada da deprem ivmesi dikkate alınarak analizler tamamlanmıştır. Tarama kazısı modellenmeden önce yerdeğiştirmeler sıfırlanarak mevcut durum modele yansıtılmıştır. Tarama kazısı sonrası oluşacak yeni yerdeğiştirmeler modelde gösterilmiştir. Meydana gelen düşey ve yatay yerdeğiştirmeler $1 \mathrm{~cm}$ 'nin altında elde edilmiştir ve bu aşamada tünel stabilitesi sağlanmıştır (Şekil 26 ve 27). Bu durum tünel destek sistemlerinin taşıma kapasitesinin yeterli olduğuna işaret etmektedir (Şekil 28). Burada çelik iksa ve püskürtme betonuna etki eden kesit tesirlerinin tahkimat kapasite zarfı içerisinde yer aldı̆̆ 1 görülmektedir.

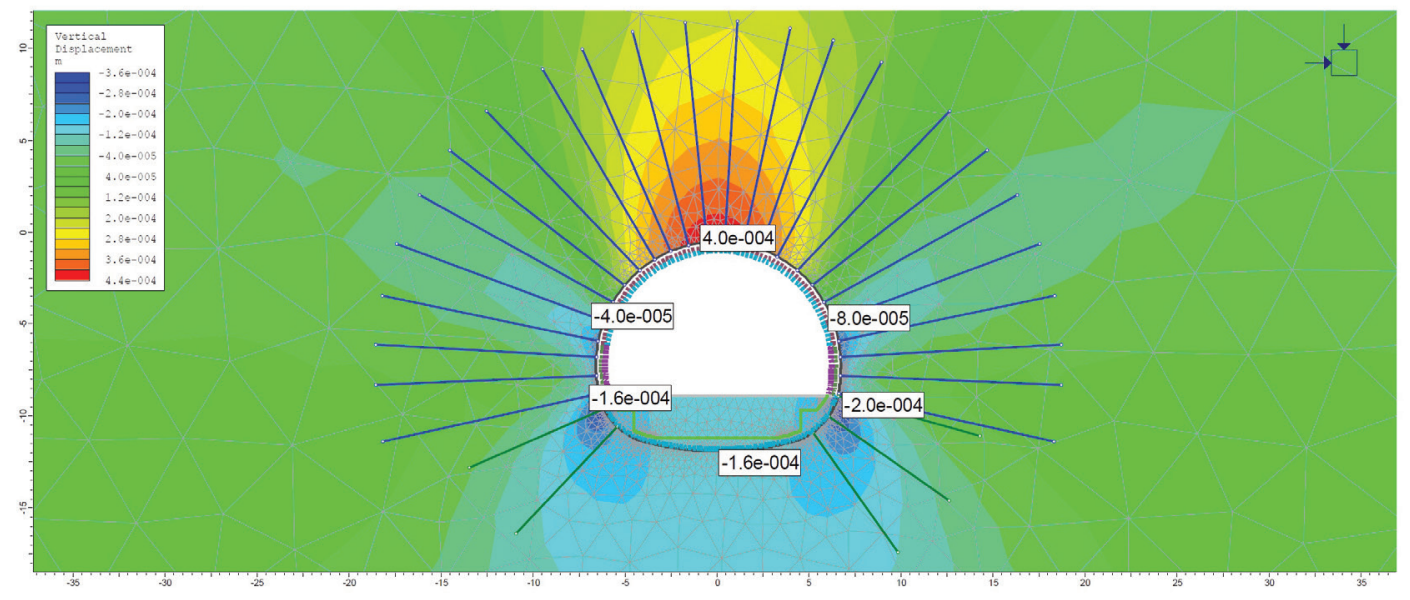

Şekil 26. Tarama kazısı sonrası düşey yerdeğiştirmeler.

Figure 26. Vertical displacements after the re-profiling excavations. 


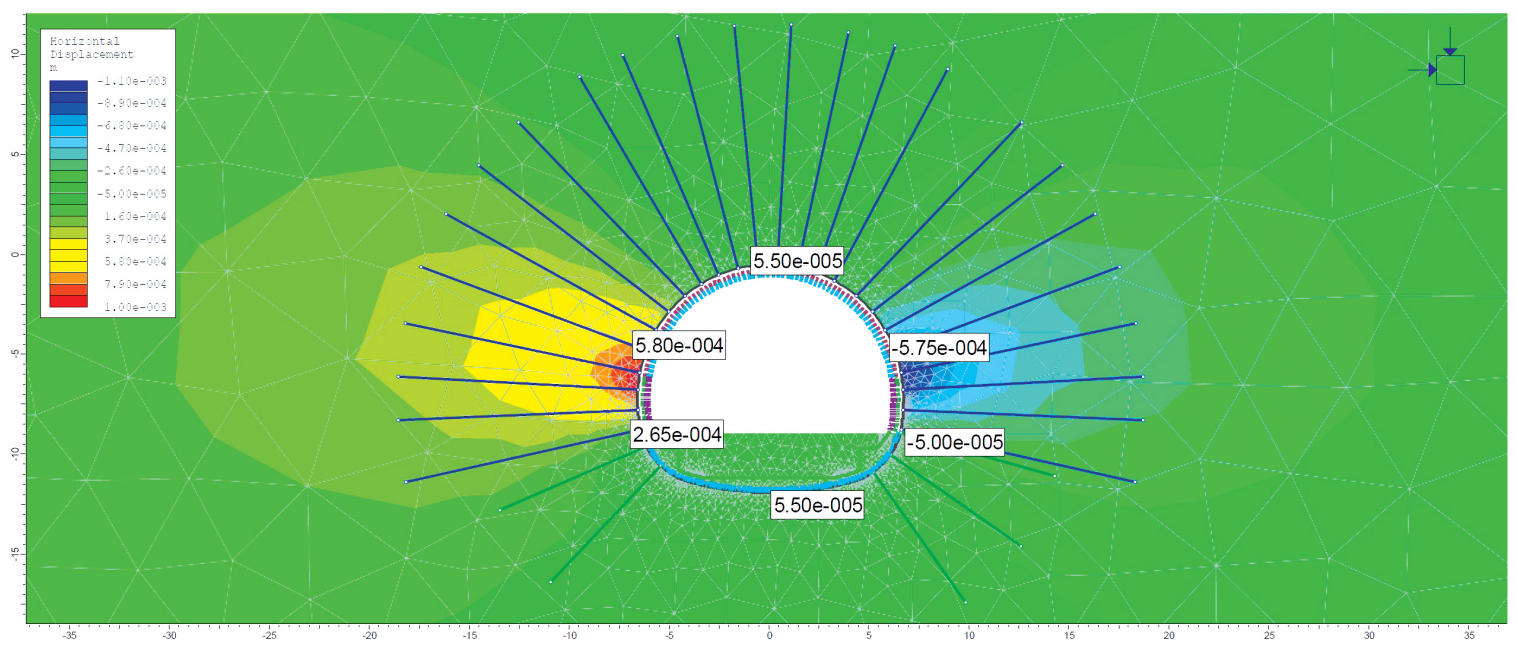

Şekil 27. Tarama kazısı sonrası yatay yerdeğiştirmeler.

Figure 27. Horizontal displacements after the re-profiling excavations.
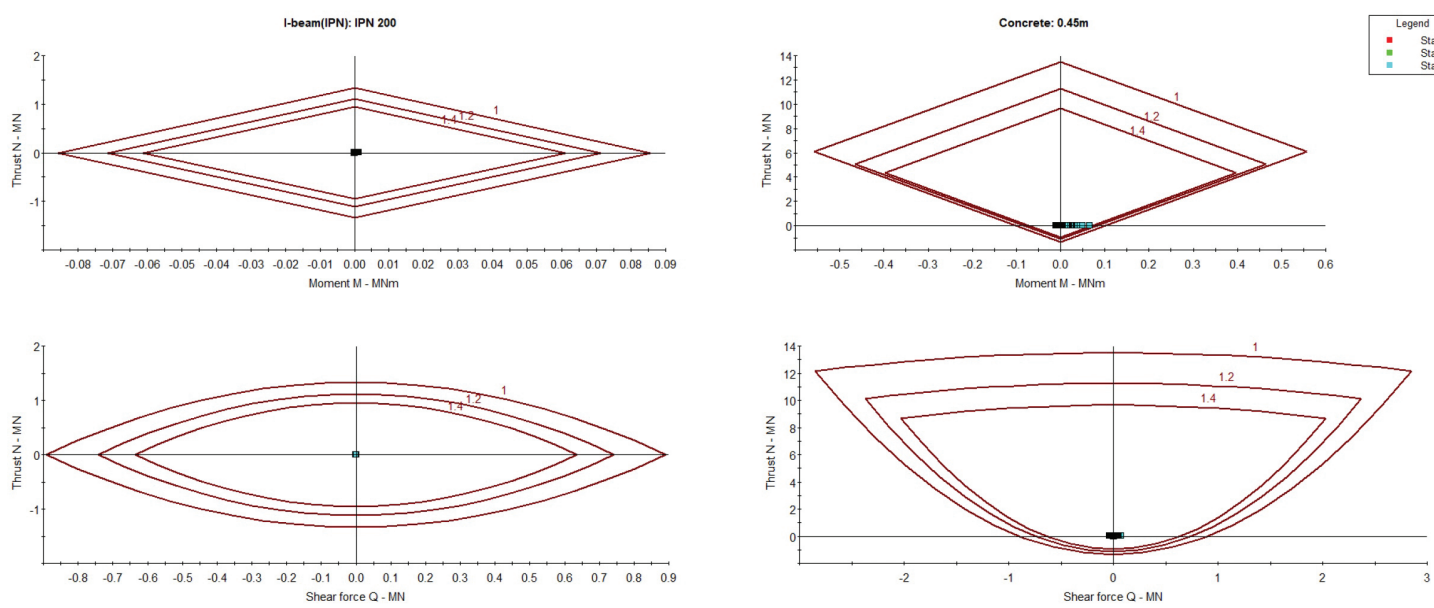

Support Element: Üst Yarı PB

Şekil 28. Tarama kazısı sonrası tahkimat kapasite eğrileri.

Figure 28. Support capacity graphs after the re-profiling excavations.

\section{TARTIŞMA VE SONUÇLAR}

$\mathrm{Bu}$ çalışma kapsamında T36 tüneli fay zonu kesimi için analitik çözümlerde kısa ve uzun dönem zemin parametrelerinee göre tünel stabilitesinin sağlanmasina yönelik analitik incelemeler yapılmıştır. Uzun dönem parametrelerin dikkate alındığı ve eşitlikler kullanılarak gerçekleştirilen analizlerde daha yüksek deformasyon sonuçları elde edilmiştir. Devamında gerçekleştirilen bilgisayar destekli sayısal analizler uzun dönem parametreleri kullanılarak tekrar incelenmiştir. Hem analitik hem de nümerik analizlerde T36 tünelinin fay 
zonu kesiminde aşırı deformasyonların oluşacağı öngörülmüştür. Bu sonuçlar tünel kazısı sırasında ölçülen yüksek deformasyon değerleriyle doğrulanmaktadır. Uzun dönem parametrelerinin kullanıldığı durum yerindeki şartları daha iyi tanımlamakla birlikte, süren ve ayna blonları gibi geçici destek elemanları kısa dönem parametrelerine göre değerlendirilmelidir.

Zayıf zeminlerde ve fay zonlarında karşılaşılan en büyük sorun zeminlerin sıkışma ve şişme davranışlarıdır. Özellikle örtü yüksekliğinin fazla olduğu tünellerde bu durum daha da kritik olmaktadır.

Fay zonlarında ve zayıf zeminlerde, plastik zon ve deformasyonlar çok hızlı bir şekilde gelişmektedir. Bu nedenle, tünel ayna ve tavan stabilitesi çok önem kazanmaktadır. Kazı öncesinde yapılacak olan ayna bulonları ile sürenler, deformasyonların hızlı gelişmesini önlemek için tünel desteklemeleri hemen yapılmalıdir. Aksi durumda deformasyon hızı denetlenmeyecek bir şekilde artmakta ve sonucunda yenilme gerçekleşmektedir.

Fay zonlarındaki kil zeminlerin koheziv özellikte olduğu düşünüldüğünde, kazıdan hemen sonra tünel aynasinda ani yenilmelerin oluşmayacağı çıkarımı yapılabilir. Ancak gerçekleştirilen analitik ve sayısal incelemelerin sonuçlarından da anlaşıldığı üzere, ayna yüzeyinin geçici elemanlarla desteklenmemesi durumunda yenilmeye kadar ilerleyen deformasyonlar oluşmaktadır.

Çalışma kapsamında gerçekleştirilen analiz sonuçlarına göre, T36 tünelinin fay zonu kesiminde tünel çevresindeki plastik zon çok hızlı genişleme eğilimi göstermiştir. $\mathrm{Bu}$ nedenle, tünel zemin-destek karakteristik eğrilerinde tünel destek basıncının sahayı temsil edici olması hayati bir öneme sahiptir. Tersi durumda, bu tür ortamlarda yapılacak kazılar sırasında gerçekleşen deformasyonlar çok hızlı seyretmekte ve durdurulması çoğu zaman imkansız hale gelmektedir.

Çalışma kapsamında incelenen T36 tünelinin fay zonu kesiminde sıkışmaya bağlı olarak ortaya çıkan sorunlar, ortamın doğru tanımlanmasıyla ve doğru analizler yapılarak giderilmiştir. Böylece, doğru tanımlanan destek elemanları fay zonu boyunca kullanılmıştır. Uzun yıllar hizmet verecek olan ulaşım tünellerinin özellikle fay zonu kesimlerinde uzun dönem parametrelerinin mutlaka dikkate alınması gerekir. İç kaplama betonunun donatılı olarak yapılması da fay zonunun stabilitesinin sağlanması açısından oldukça önemlidir. Çünkü tünel örtü kalınlığ yüksek olsa dahi, fay zonlarında fay breşleri ve killerle karşılaşılmaktadır. $\mathrm{Bu}$ tür doğal malzemeler problemli zemin davranışları göstermekte ve tünelcilik açısından ciddi olumsuzlukların yaşanmasına neden olmaktadır.

\section{KATKI BELİRTME}

Yazarlar bu çalışmanın hazırlanması sırasında verdikleri destekten dolay1 TCDD Genel Müdürlüğü'ne ve Fugro Sial Yerbilimleri'ne teşekkür ederler.

\section{KAYNAKLAR}

Akgün, H., Muratlı, S.W., Koçkar, M.K., 2014. Geotechnical investigations and preliminary support design for the Geçilmez tunnel: A case study along the Black Sea coastal highway, Giresun, Northern Turkey. Tunnelling and Underground Space Technology, 40, 277 - 299.

Aygar, E., 2000. A Critical approach to the New Austrian Tunneling Method in Bolu Tunnels. Hacettepe University, Department of Mining Engineering, Ankara, Master Thesis, pp 276. 
Aygar, E., 2007. Investigation of the Bolu Tunnel Stability by Means of Static and Dynamic Analyses. Hacettepe University, Department of Mining Engineering, Ankara, PhD Thesis, 273 p.

Aygar, E., 2020. Evaluation of New Austrain Tunneling Method applied to Bolu tunnel's weak rocks. Journal of Rock Mechanics and Geotechnial Engineering, 12(3), 541-556.

Aygar, E.B., Gokceoglu, C., 2019. Ankara-İstanbul High Speed Railway Projects, the problems encountered at T13 Tunnel Fault Zone and solution suggestions, Proceedings of the $26^{\text {th }}$ International Mining Congress and Exhibition of Turkey, 197-205.

Aygar, E.B., Gokceoglu, C., 2020a. Problems encountered during a railway tunnel excavation in squeezing and swelling materials and possible engineering measures: a case study from Turkey. Sustainability, 12, 1166, https://doi.org/10.3390/ su12031166.

Aygar, E., Gökçeoğlu, C., 2020b. Bir tünelde portal ve tünel stabilitesi ilişkisi (Ankara - Sivas Yüksek Hızlı Demiryolu Projesi, T3 Tüneli). Bilimsel Madencilik Dergisi, 59 (3), 157-168.

Aygar, E., Gökçeoğlu, C., 2020c. Zayıf zeminlerde açılan büyük çaplı bir tünelin destek sistemi tasarımı (Çukurçayır-2 Tüneli, Trabzon). Yer Alt1 Kaynakları Dergisi, 18, 97-118.

Aygar, E., Gökçeoğlu, C., 2020d. Kohezyonsuz zeminde tünelcilik (T12 Tüneli, Bursa - Yenişehir Yüksek Hızlı Tren Demiryolu Projesi): sorunlar ve çözümler. Yer Mühendisliği, 14 (8), 26 - 34.

Barton, N.R., Lien, R., Lunde, J., 1974. Engineering classification of rock masses for the design of tunnel support. Rock Mechanics, 6(4), 189-239.

Barton, N., Løset, F., Lien, R., Lunde, J., 1980. Application of the Q-system in design decisions. In subsurface space, (ed. M. Bergman) New York: Pergamon 2, 553-561.

Bieniawski, Z.T., 1973. Engineering classification of jointed rock masses. Transaction of the South African Institution of Civil Engineers, 15, 335344.
Bieniawski, Z.T., 1976. Rock mass classification in rock engineering. In exploration for rock engineering, Proc. of the Symp., (ed. Z.T. Bieniawski), Cape Town: Balkema, 1, 97-106.

Bieniawski, Z.T., 1989. Engineering Rock Mass Classifications. New York: Wiley.

Brady, B.H.G., Brown, E.T., 1985. Rock Mechanics for Underground Mining. London: Allen and Unwin.

Das, R., Singh, P.K., Kainthola, A., Panthee, S., 2017. Numerical analysis of surface subsidence in asymmetric parallel highway tunnels, Journal of Rock Mechanics and Geotechnical Engineering, 9, 170-179.

Fenner, R., 1938. Untersuchungen zur erkenntnis des gebirgsdrucks. Glückauf, 74 (32), 681-695.

Fugro Sial Yerbilimleri Ltd. Şti., 2009. 36 nolu tünel jeolojik-jeoteknik raporu ve tünel proje hesap raporu, Ankara.

Fugro Sial Yerbilimleri Ltd. Şti., 2011. T36 Tüneli tarama kazı için gerekçe raporu, (Km:243+100 ile Km:242+960), Ankara.

Gibson, R.E., 1953. Experimental determination of the true cohesion and true angle of internal friction in clays. Proceedings of the Third International Conference on Soil Mechanics and Foundation Engineering, Zurich, Volume 1, 126-130.

Grimstad, E., Barton, N., 1993. Updating the Q-System for NMT. Proc. int. symp. on sprayed concrete - modern use of wet mix sprayed concrete for underground support, Fagernes. 4666. Oslo: Norwegian Concrete Assn.

Hoek, E., Brown, E.T., 1980. Underground Excavations in Rock. London: Instn Min. Metall $527 \mathrm{p}$.

Hoek, E., 2007. Practical Rock Engineering, https:// www.rocscience.com/ assets/resources/learning/ hoek/Practical-Rock-Engineering-Full-Text.pdf $341 \mathrm{p}$.

Hoek, E., 2012. Rock Support Interaction analysis for tunnels in weak rcok masses, https://www. rocscience.com/documents/pdfs/rocnews/ winter2012/Rock-Support-Interaction-Analysisfor-Tunnels-Hoek.pdf 
Aygar, Gokceoglu

Hoek, E., Guevara, R., 2009. Overcoming squeezing in the Yacambú-Quibor tunnel, Venezuela. Rock Mechanics and Rock Engineering, 42(2), 389418.

Hoek, E., Marinos, P., 2000. Predicting tunnel squeezing. Tunnels and Tunnelling International. Part 1 - November 2000, Part 2 - December 2000.

Hoek, E., Carranza-Torres, C., Diederichs, M.S., Corkum, B., 2008. Integration of geotechnical and structural design in tunnelling. In: Proceedings University of Minnesota 56th Annual Geotechnical Engineering Conference, 29 February 2008. Minneapolis, pp. 1-53. Available for downloading at Hoek's Corner at $<$ www.rocscience.com>.

Koçkar, M.K., Akgün, H., 2003. Methodology for tunnel and portal support design in mixed limestone, schist and phyllite conditions: a case study in Turkey. International Journal of Rock Mechanics and Mining Sciences, 40, 173 - 196.

Mahmutoğlu, Y., Vardar, M., Koçak, C., 2006. Tunnelling difficulties under squeezing and flowing conditions at Ayaş. Felsbau Rock and Soil Engineering, 24 (5), 44-50.

Moussaei, N., Sharifzadeh, M., Sahriar, K., Khosravi, M.H., 2019. A new classification of failure mechanisms at tunnels in stratified rock masses through physical and numerical modelling. Tunnelling and Underground Space Technology, 91, 103017.

Müller L., 1978. Removing misconceptions on the New Austrian Tunnelling Method. Tunnels and Tunnelling International,10(8), 29-32.

Panthi, K.K., Basnet, C.B., 2019. Evaluation of earthquake impact on magnitude of the minimum principal stress along a shotcrete lined pressure tunnel in Nepal. Journal of Rock Mechanics and Geotechnical Engineering, 11, 920-934.
Rabcewicz, L.V., 1964a. The New Austrian Tunnelling Method, Part One, Water Power, pp 453-457.

Rabcewicz, L.V.,1964b. The New Austrian Tunnelling Method, Part Two, Water Power, pp 511-515.

Rabcewicz, L.V., 1965. The New Austrian Tunnelling Method, Part Three, Water Power, pp 19-24.

Rabcewicz L. V., Golser J., 1973. Principles of dimensioning the supporting system for the "New Austrian Tunnelling Method". Water Power, 88-93.

RocScience, 2020. Phase2 8.0 User Guide, https:// www.rocscience.com/downloads/phase2/ Phase2_TutorialManual.

Schubert, W., 1996. Dealing with squeezing conditions in Alpine tunnels. Rock Mechanics and Rock Engineering, 29(3), 145-153.

Terzaghi, K., 1946. Rock defects and loads on tunnel supports. In Rock tunneling with steel supports, (eds R. V. Proctor and T. L. White) Youngstown, $\mathrm{OH}$ : Commercial Shearing and Stamping Company, 1, 17-99.

Terzaghi, K., Peck, R. B., Mesri, G., 1996. Soil Mechanics in Engineering Practice, John Wiley \& Sons, Inc., Third Edition, New York.

Unlu, T., Gercek, H., 2003. Effect of Poisson's ratio on the normalized radial displacements occurring around the face of a circular tunnel. Tunnelling and Underground Space Technology, 18, 547553.

Vlachopoulos, N., Diederichs, M.S., 2009. Improved longitudinal displacement profiles for convergence confinement analysis of deep tunnels. Rock Mechanics and Rock Engineering, 42 (2), 131-146.

Zou, J., Chen, G., Qian, Z., 2019. Tunnel face stability in cohesion-frictional soils considering the soil arching effect by improved failure models. Computers and Geotechnics, 106, 1-17. 